STRAIN DISTRIBUTION ANAL YSIS IN RING UPSET FORGING AND HOT-ROLLING BY PHOTOPLASTICITY

Adeyinka Kofoworola Oyinlola

Ph. D. Thesis Submitted to Iowa State University

Ames Laboratory, ERDA

Iowa State University

Ames, Iowa 50011

Date Transmitted: June 1976

PREPARED FOR THE U.S. ENERGY RESEARCH AND DEVELOPMENT ADMINISTRATION UNDER CONTRACT NO. W-7405-eng-82

This report was prepared as an account of work the United States nor the United States Energy Research and Development any their contractors, their employees, their employees, makes any

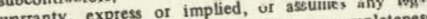
Wer sesponsibility for the accuracy, completeness or usefulness of any information, apparatus, product or rncess disclosed, or represents that its wese wold not infringe privately owned tightits. 


\section{DISCLAIMER}

This report was prepared as an account of work sponsored by an agency of the United States Government. Neither the United States Government nor any agency Thereof, nor any of their employees, makes any warranty, express or implied, or assumes any legal liability or responsibility for the accuracy, completeness, or usefulness of any information, apparatus, product, or process disclosed, or represents that its use would not infringe privately owned rights. Reference herein to any specific commercial product, process, or service by trade name, trademark, manufacturer, or otherwise does not necessarily constitute or imply its endorsement, recommendation, or favoring by the United States Government or any agency thereof. The views and opinions of authors expressed herein do not necessarily state or reflect those of the United States Government or any agency thereof. 


\section{DISCLAIMER}

Portions of this document may be illegible in electronic image products. Images are produced from the best available original document. 
This report was prepared as an account of work sponsored by the United States Government. Neither the United States nor the United States Energy Research and Development Administration, nor any of their employees, nor any of their contractors, subcontractors, or their employees, makes any warranty, express or implied, or assumes any legal liability or responsibility for the accuracy, completeness, or usefulness of any information, apparatus, product or process disclosed, or represents that its u'se would not infringe privately owned rights.

Available from: National Terhnical Information Service U. S. Department of Commerce P.O. Box 1553

Springfield, VA 22161

Price: Microfiche $\$ 2.25$ 


\title{
Strain distribution analysis in ring upset forging and hot-rolling by photoplasticity
}

by

\author{
Adeyinka Kofoworola Oyinlola \\ A Dissertation Submitted to the \\ Graduate Faculty in Partial Fulfillment of \\ The Requirements for the Degree of \\ DOCTOR OF PHILOSOPHY \\ Department: Materials Science and Engineering \\ Major: Metallurgy (Mechanical Metallurgy)
}

Approved:

T. E. Scott

In Charge of Major Work

For the Major Department

For the Graduate college

Iowa State University

Ames, Iowa

1976 
TABLE OF CONTENTS

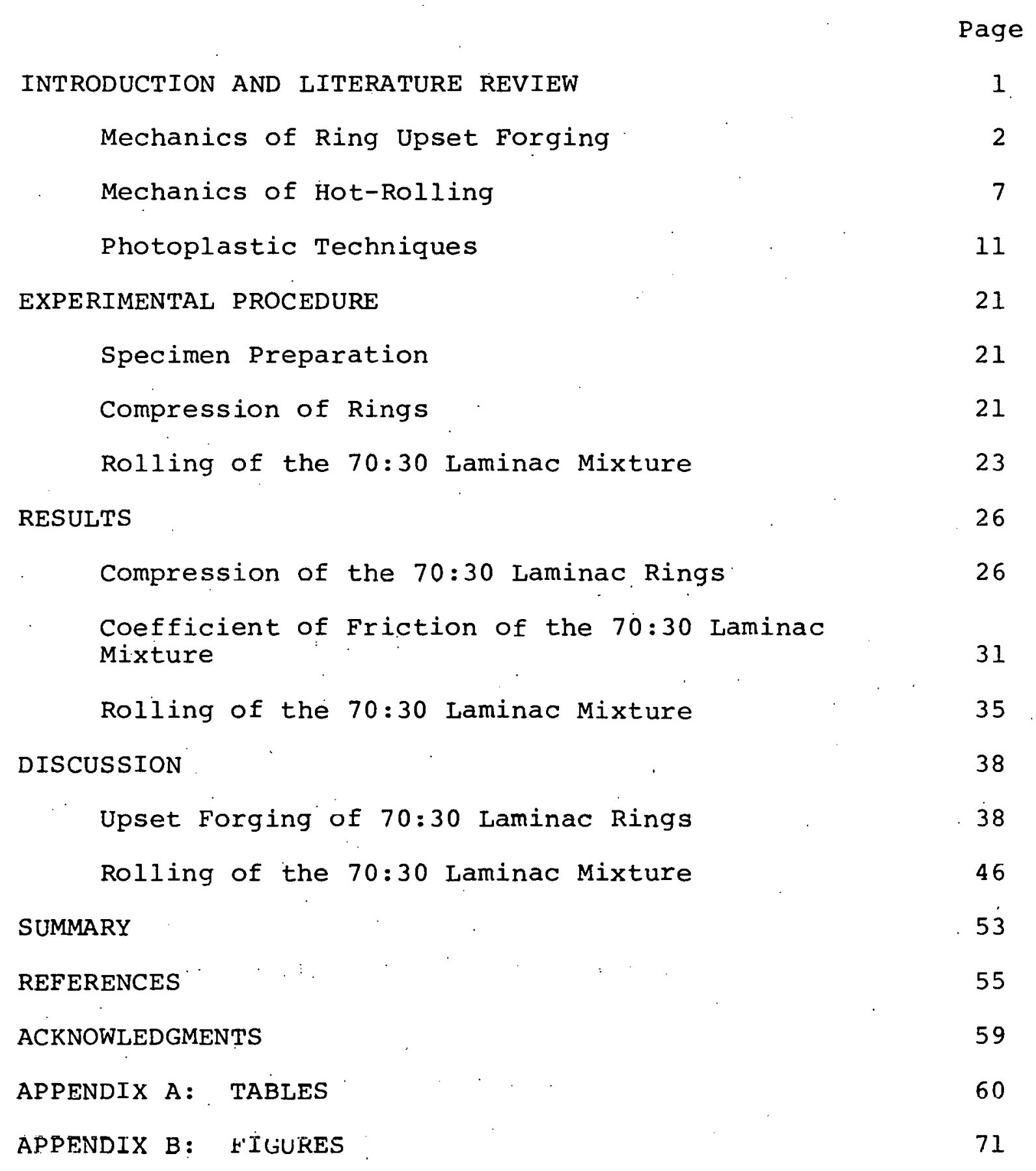


Strain distribution analysis in ring upset forging and hot-rolling by photoplasticity

Adeyinka Kofoworola oyinlola

Under the supervision of T. E. Scott

From the Department of Materials Science and Engineering Iowa State University

Laminac, a photomechanic material which exhibits visible light birefringence at strains beyond the elastic limit, was employed to determine the three dimensional strain distribution in upset forged rings and in hot rolled bars. Specifical$1 y$, a mixture of $70 \%$ rigid Laminac 4116 and $30 \%$ flexible Laminac 4134 polyester resins was used. This mixture when tested at $51^{\circ} \mathrm{C}$ provides a stress-strain curve that exhibits little or no strain hardening and simulates, at least in the first approximation, the characteristics of aluminum when it is deformed at about $425^{\circ} \mathrm{C}$. Using photoplasticity techniques, the three dimensional strain distribution along the midsection of rings was determined. The Male-Cockcroft (l) empirical method for determining coefficients of friction was applied in part to 70:30 Laminac rings compressed between various platens with different surface characteristics. The neutral radius and the interfacial friction factor for compressed rings were determined by Avitzur's (2) analytical method and compared with the experimental values. The neutral radius 
values correlated very well.

By sectioning rolled billets of 70:30 Laminac, it was possible to determine the three dimensional strain distribution produced by rolling. Billet geometry and roll speed influence the severity of double bulge formation that occurs in hot-rolled aluminum in commercial production. A good correlation was established regarding lateral spread in the rolling of 70:30 Laminac blocks and the spread predicted by the theory of on and Kobayashi (3).

1. Male, A. T., and M. G. Cockcroft. "A Method for the Determination of the Coefficient of Friction of Metals Under Condition of Bulk Plastic Deformation." Journal of the Institute of Metals 93 (1964), 38-46.

2. Avitzur, B. "Forging of Hollow Discs." Israel Journal of Technology 2, No. 3 (1964); 295-304.

3. Oh, S. I., and Shiro Kobayashi. "An Approximate Method for a Three-Dimensional Analysis of Rolling." International Journal of Mechanical Sciences 17 (1975), 295-305. 


\section{INTRODUCTION AND LITERATURE REVIEW}

Metal forming processes date back 3000 years. Their importance, then and now, is included in the fact that the majority of manufactured metallic products require in part, or totally, a forming operation. Despite the long existence and use of certain forming operations such as hot rolling, cold rolling, drawing, sinking, swaging and extruding, high forming yields have not been achieved in many areas of industrial production. This is due largely to lack of understanding, or to complete ignorance, of some forming parameters. In order to improve the forming process and the sequence which yields the desired final product., the effects of parameters such as strain, strain rate, friction, temperature, billet size etc., on forming operations and their products must be understood better.

One of the key requirements for more precise analyses of deformation forming processes is an accurate description of the three-dimensional states of stress or strain within a body undergoing plastic deformation. Coupled with this, is the need to understand the extent to which friction between the work piece and die influences the three-dimensional strain distribution in the deformed body. Friction is, with sume significant exceptions, an unwanted factor with a number of undesirable side effects. In general, it raises the forces 
and the power requirements, subjects the deformation tool to higher pressure, renders deformation less uniform within the work piece, raises the temperature of the interface and may set limits to the maximum obtainable deformation.

A survey of the literature regarding forming operations in general revealed that a complete strain distribution has not been established even for unidirectionally rolled billets. Presumably, this is a consequence of the fact that no reliable method is available for establishing three-dimensional strain distributions associated with different sequences of rolling or, for that matter, for most forming operations. A simulative material as well as an experimental technique with a capability for providing three-dimensional strain distribution is sorely needed. It is towards this goal that the present research is directed. A thorough understanding of the three-dimensional strain or stress distribution obtained with modelling materials could help solve some of the problems encountered in commercial forming operations.

\section{Mechanics of Ring Upset Forging}

The importance of friction in all forming operations has led to the development of various experimental methods to determine the coefficient of friction and how it affects deformation processes. Among the early pioneers in this field. of research were Male and Cockcroft (1) who developed an 
experimental test called the ring compression test for the determination of the coefficient of friction of metals under conditions of bulk plastic deformation. Their experiment involves a simple upset forging operation carried out on a flat ring-shaped specimen. The coefficient of friction is related to the change of internal diameter produced by a given amount of compression in the thickness direction. Based on their experiment, an empirical formula, through which the change in internal diameter is related to the coefficient of friction, was developed. The empirical formula they gave had the form $\Delta D=m \ln \left(\frac{\mu}{0.055}\right)$, where $m$ is given by: In $m=(0.044 x$ deformation percentage $)+10.6, \Delta \mathrm{D}$ is the percentage decrease in internal diameter of a ring upon compression and $\mu$ is the coefficient of friction. As will be shown later, this formula is incorrect.

A major setback of the method is that a satisfactory theoretical analysis of the compression of a ring is not yet available. Consequently, numerical values of the coefficient of friction $\mu$ can be obtained only by an independent calibration method. The simplified analysis attempted by Male and cockcroft did not fit their experimental results that were obtained presumably because effects due to barrelling of the specimen could not yet be treated theoretically. Nevertheless, the ring compression test is often used to determine the coefficient of friction between the die and the 
work piece.

The change in geometry during upset forging of hollow discs has been investigated analytically in recent years. Avitzur (2) developed a mathematical expression for the flow of the inner and outer radii of a disc as a function of the motion of the platens, dimensions of the disc, and friction between disc and platens. By using the minimum power approach which he called the Lower Upper Bound solution, the neutral radius was determined based on the assumption of a constant shear factor between platen and disc. The material was assumed to obey Levy-Mises stressstrain rate relations, implying no strain hardening effect, no elastic deformation and consequently no volume change. The major disadvantage of this mathematical expression is that the assumed velocity field produces a stress distribution which does not satisfy the boundary condition of the interface between disc and platens. The point-by-point agreement with actual conditions cannot be judged without the exact solution or an elaborate experimental study.

Plasticity theory analysis of geometry changes during compression of hollow cylinders have been insufficiently developed or their method of application has been very involved. Therefore, Hawkyard and Johnson (3) developed a simple means of predicting strains in the deforming cylinder from a series of curves which were obtained from geometry 
changes during the compression process of the cylinders.

From stress equilibrium considerations, they determined the current position of the neutral surface from which radial movement originates and hence deduced the incremental strain or strain rate pattern. The geometric changes throughout the process were obtained by integrating the incremental strains at the inner and outer surfaces. In their analysis they assumed that there was no barrelling, thereby, making the actual conditions very simple. Such an assumption will definitely increase the error with increasing frictional stress and increasing cylinder height. An in-depth study of the hale and cockcroft method of determining the coefficient friction was made by Van Sant (4) whereby a mathematical technique was developed that enables the friction effect to be considered quantitatively. The validity of the proposed mathematical analysis which depends on an assumed expression for the neutral radius has not been checked with experiment.

The practicality of some existing forming theories has been based on simultaneous fulfillment of two conditions; a) the plastic zone is narrow in one direction and b) there is a high degree of symmetry (usually axial), effectively reducing the number of independent coordinates to one. Where either of these conditions does not obtain, no mathematically respectable theories appear to be available, 
even for simple basic forming operations such as flat tool forging or hot-rolling of rectangular sections.

Taking these facts into consideration, Hill (5) proposed a new method of analysis for any technological forming process. This analysis, he claimed, is applicable to any material which is plastic in a broad sense, and whatever the friction or tool geometry. The procedure of his method involves choosing initially a class of velocity fields from which the best approximation is eventually taken. The chosen velocity field has to satisfy the static requirements.

Recently, Lahoti and Kobayashi (6) employed Hill's analysis to explore the modes of deformation in ring compression with barrelling. They investigated the nonuniformity of flow in the thickness direction. The neutral radius at various stages of deformation was determined by assuming the neutral radius to be independent of the bulge formation during compression. They found that the geometrical changes obtained by Hill's method agreed very well with previously reported theoretical works.

The major advantages of the aforementioned methods of studying friction at yielding surfaces are that no direct measurement of force is required, and no yield strength values are needed, hence the major difficulties of compression testing at high temperatures or high strain rates are eliminated. What these methods have failed to produce' 
is the true spectrum of the internal strain distribution starting from the internal diameter to the outside diameter of axially compressed rings whose geometries have been chosen to prevent barrelling.

\section{Mechanics of Hot-Rolling}

Most of the well-known theories of rolling (7) have been developed to predict the load and torque required by the rolling mill, and possibly the lateral spread when billets having width to thickness ratios larger than 6 or 10 are rolled. In the formulation of these widely known theories, a number of basic assumptions (7) were made, e.g.: the metal being formed is a continuous isotropic medium; homogeneous deformation; constant yield stress during the pass; circular arc of contact; mathematical approximations; constant coefficient of friction along the arc of contact; plane strain by neglecting lateral spread; the Huber-Von Mises condition of plasticity; slipping takes place along the length of the arc of contact; elastic compression of the strip is negligible; small contact angle and constant speed of rolling. When rolling sections which have width to thickness ratios less than 6 , such as is common in hotrolling of ingots into billets, the theoretical predictions become unreliable and predictive work has to resort to empirical formulas with limited ranges of application. The 
most recent empirical formulations are due to El-Kalay and Sparling (8), Helmi and Alexander (9) and Beese (10).

The rolling process is complicated, by many factors, to the extent that it is not possible to obtain a solution for even the relatively simple problem of flat-rolling and a proved, accurate, general solution is not yet known. Twodimensional states of strain or stress have been described analytically for the rolling process using the aforementioned assumptions (7). Knowledge of three-dimensional strain or stress states and how they vary with work piece geometry and other process variables will help improve existing theories and probably will lead to the development of new theories or accurate numerical methods. such as the finite element approach.

Different approaches have been taken by different investigators to gain information about the strain distribution within a body undergoing plastic deformation during hotrolling. Experimental techniques employed to obtain this type of information typically involve the placement of grids of one material into another model material. The composite material is deformed, sectioned, and the displacements usually in only two dimensions, are measured. For example, Averbach (11) determined the distribution of principal strains within a cast bar of tin by radiographing an embedded network of lead containing squares approximately $2.1 \mathrm{~mm}$ wide (144 network 
squares per square inch) after a $20 \%$ rolling reduction. His results were computed from only two vertical sections where he was able to evaluate the longitudinal and vertical strains directly from the radiographs. The lateral strains were totally neglected based on the fact that they were too small for accurate measurement. Instead, he evaluated the lateral strains by invoking the constancy of volume condition. This condition would have to be in error by $50 \%$ to account for the observed lateral strains; however, deviations of this magnitude were not observed.

Orowan (12) studied plastic flow in rolling by partrolling wide slabs composed of alternate layers of gray and white plasticine between unpolished wooden rolls. These conditions established a coefficient of friction greater than one, thereby providing for complete sticking to occur. After the laminated plasticine slabs were part-rolled, they were withdrawn from the rolls and split longitudinally at the center line to reveal the strain distribution. Orowan neglected observations which were not amenable to analysis within the framework of the mathematical formulation of his rolling theory. For example, the deformation which occurred at the entry side of the mill where the material is squeezed backwards out of the roll gap could not be incorporated in his analysis. Furthermore, he assumed a small angle of contact but obtained large angles of contact in his experiment. 
This led to considerable error in his calculations. (An anslysis appropriate to large angles of contact needs to be formulated.) Nevertheless, Orowan's theory of rolling seems to stand as the best available since his theory avoids the usual assumption that deformation can be regarded as a homogeneous compression locally and takes into account the inhomogeneity of stress distribution. Furthermore, his theory takes into consideration any given variation of the yield stress and of the coefficient of friction along the arc of contact.

A few attempts have been made recently regarding threedimensional analysis of rolling. Oh and Kobayashi (13) proposed a theory based on an extremum principle for rigid perfectly plastic material to analyze the three-dimensional deformation in rolling. They obtained theoretical solutions for single-pass rolling in terms of sidewise spread, roll torque and the location of a neutral point. Their theory revealed the fact that the amount of spread decreases as initial width-to-thickness ratio increases and as the initial thickness with respect to roll diameter increases. Previous experimental results based on this fact correlated excellently with their theoretical results. Their theory also agrees excellently with experimental results from rolling of lead (14) which shows that roll torque increases with increasing reduction and with increasing initial thickness. From their 
theoretical calculations, they claimed that there is a small increase in torque with increasing friction at low reductions. They reported that by decreasing the friction the neutral point moved toward the exit plane.

Despite the excellent agreement with experimental results, their theory was based on the assumption of a class of surface shapes followed by the determination of the velocity field which minimizes the functional for the assumed surface shape. The minimization was achieved by assuming a class of velocity fields for all shapes assumed and from these velocity fields, the steady-state velocity field and corresponding surface shape was found. The accuracy of their results depends on how closely the assumed surface shapes and velocity field approximate the actual solution.

\section{Photoplastic Techniques}

Photoelasticity is that branch of experimental stress analysis which utilizes the phenomenon exhibited by some transparent materials which are optically isotropic when free of stress but become temporarily birefringent (i.e., they are temporarily doubly refractive) in the directions of the principal strains or stresses when loads are applied to them. Models made from such materials can therefore be used to obtain information regarding the stress or strain distributions in materials subjected to various systems of loads $(15,16)$. 
When viewed in a field of polarized light, the birefringence manifests itself as an optical interference pattern of light and dark bands called fringes which may be due to stress, strain, or a combination of the two, depending on the model material being used.

There arise two simultaneous sets of interference fringes which are generally called "isochromatics" and "isoclinics." It has been established that in the region of linear elastic response the isochromatics are proportional to the in-plane maximum shear stresses while the isoclinics give the in-plane pxincipal stress directions. The two sets of fringes can be separated by suitable arrangement of the optical elements of the polarized light field or "polariscope.". The quantitative relationship, which has been shown to exist between the stress and/or strain state and the optical effect, provides a precise experimental means for evaluating stress or strain distributions in extremely complicated two- or three-dimensional configurations. The method of photoelasticity has been applied to a wide variety of engineering problems which proved difficult or impossible to solve by analytical means and often provides new insight to difficult problems leading to additional mathematiral development.

Experimental evidence to date indicates that the optical effects produced by stress and/or strain in transparent materials exists for both elastic and plastic deformations. 
Hetenyi (17) used the results of tensile tests to study plastic strains in a.nylon copolymer. He found that the isochromatics could be related to the strain distribution in this material. Emphasis in his study was placed on optical indications of yielding. Fried and shoup (18) used polyethylene to study the photoelastic effect in a region of large deformation, and found that the optical retardation varied linearly with the principal strain difference well beyond the range of linear stress-strain behavior. Their photoelastic model predictions of strain distributions compared favorably with those present in an aluminum prototype. More recently Brill (19) selected polycarbonate as the model material for basic studies in one- and two-dimensional photoplasticity. He concluded that the birefringence is a function only of the principal strain difference and that the isoclinic parameter provided a measure of the principal strain directions. A tensile specimen with a central circular hole was used and the photoplastic results were compared with test results from metallic analogues. Good agreement was obtained.

Extensive studies of celluloid as a photoplastic material for determining factors of stress concentration and strain distributions have been made by Fried (20), Frocht and Thomson (21), Frocht and Cheng (22), and Mönch and Loreck (23). Polycarbonate material was first suggested by Ito (24); Gurtman, Jenkins and Tung (25), Brinson (26), and Whitfield 
(27) have shown the applicability of polycarbonate material to elasto-plastic problems. Loreck (28) conducted studies of the mechanical and optical properties of a polyester material to determine its applicability as a possible photoelastic material. Dally and Mulc (29) recently made an in-depth study of polycarbonate as a model material for three dimensional photo-plasticity and established the strain-optic law relating the permanent plastic strains to the observed optical. response.

In all of these previous studies attempts were made to apply the principles of photoelasticity to studies of plastic deformation in small zones of a specimen in regions of high stress concentration (30). Design of such components is usually based on theory-of-elasticity considerations. A major difficulty always encountered when attempting to obtain stress or strain information by photoplastic methods is the selection of a model material which has stress-strain characteristics that simulate the real material. Several of the model materials mentioned previously were satisfactory on the limited scales required by the problems which were solved. Since these tests were usually in two-dimensions and involved only limited plastic deformations, they do not appear to provide much insight. into the phenomena associated with gross plastic deformation of the type encountered in forming operations. Morris and Riley (31) developed a photomechanic 
material which appeared to be well suited for studies beyond the elastic limit. According to their studies, a mixture of $60 \%$ flexible Laminac EPX $126-3$ and $40 \%$ rigid Laminac 4116 polyester resins adequately simulates the behavior of aluminum under uniaxial tension.

Recently Ohashi and Tadashi (32) determined the stress state within a plastically flowing body in plane strain by a photorheological method. They rolled $6 \mathrm{~mm}$ thick celluloid plates subjected to forward tension as well as rolling torque. They determined stresses in two dimensions and showed the effect of the applied tension on their distribution, both in the rolls and in the strip specimens. The method by which they restricted the deformation of the strip to obtain plane strain needs further investigation to evaluate the effect of the constraint on the strain distribution in the strip during rolling. The experiment was carried out at only one temperature $\left(65^{\circ} \mathrm{C}\right)$. The variation of stress distribution with temperature also needs further investigation. Only work-piece geometries involving very large length to breadth ratios have been accounted for in-rolling investigations. The application of the photo-rheological method to billet rolling needs experimental proof. Finally, the applicability of this experiment to metal rolling has not been demonstrated.

Employing photoplasticity techniques, Burger, Oyinlola 
and Scott, (33) examined the three dimensional strain distribution in rolled billets using a 60:40 Laminac mixture developed by Morris and Riley (31) as the photoplastic material. They demonstrated that the 60:40 Laminac mixture when deformed at $40^{\circ} \mathrm{C}$ simulates, at least in the first approximation, the characteristics of aluminum when it is deformed at about $425^{\circ} \mathrm{C}$. The distribution of principal shear strains determined from the fringe patterns of rolled blocks of the photoplastic material exhibited features which could be related to edge contours known to form during commercial hotrolling of aluminum.

Recently Koenig: (34) used another brand of Laminac to develop a photomechanic material which simulates the behavior of hot aluminum under uniaxial compression. A cast of $70 \%$ rigid Laminac 4116 mixed with $30 \%$ flexible Laminac 4134 polyester resins provided a stress-strain curve that exhibited little or no strain hardening. This 70:30 Laminac mixture satisfied a majority of the requirements listed by Frocht and Thomson (21) for the transition from model to real material in elasto-plastic problems. However, a recent investigation (35) revealed that the photoplastic material did not exhibit the same yield criterion that aluminum obeys. The investigators (35) observed that the ratio of compressive to tensile yield strength was approximately 1.35 whereas aluminum has equal tensile and com- 
pressive yield strengths. The other two well understood requirements satisfied by 70:30 Laminac mixture are:

a) model and real materials must have the same shape of stress-strain curve

b) the value of Poisson's ratio in the plastic range must be the same for both materials.

The material must also meet the following requirements which are listed in the experimental stress analysis textbook by Dally and Riley: (15)
a) visible light transparency
b) sensitivity to either stress or strain, as indi- cated by a low material fringe value in terms of either stress, $f_{\sigma}$ or strain, $f_{\varepsilon}$
c) isotropy
d) homogeneity
e) nonexcessive creeping
f) high modulus of elasticity
g) high ultimate strength
h) material sensitivity ( $f_{\sigma}$ or $f_{\varepsilon}$ ) should not change markedly with small variations in temperature.
i) no time-edge effects caused by absorption of water vapor
j) machinability
k) no residual stresses
1) material should not be prohibitively expensive 
Nondimensional stress-strain comparisons for aluminum and the 70:30 mixture of Laminac polyester resins under uniaxial compression are shown in Fig. 1 .

In order to compare the stress-strain behavior of different materials, the Ramberg-Osgood (36) relation is employed. This relation allows the use of dimensionless variables indicated in Fig. 1 .

The Ramberg-Osgood relation is

$$
\frac{E}{\sigma_{1}}=\frac{\sigma}{\sigma_{1}}+3 / 7\left(\frac{\sigma}{\sigma_{1}}\right)^{n}
$$

where $E$ is Young's modulus, $\sigma_{1}$ is a secant yield stress determined by a secant modulus, $E_{S}=0.7 \mathrm{E}, \sigma$ is the true stress, $\varepsilon$ is true strain, and $\mathrm{n}$ is a parameter chosen to provide the best fit to the stress-strain curve of the actual material being considered and is computed from the expression

$$
n=1+\frac{0.3853}{\log _{10} \frac{\sigma_{1}}{\sigma_{2}}}
$$

where $\sigma_{2}$ corresponds to a second secant modulus, $0.85 \mathrm{E}$.

The curves in Fig. 1 indicate that the 70:30 polyester mixture can be used to simulate the behavior of aluminum under hot working conditions.

Until the present time, all the theories of hot-rolling have been based on the various assumptions mentioned earlier. That these assumptions are not always valid can be demon- 
strated, for example, by the fact that defects such as double-edge bulging, edge cracks and other defects which are not predicted by the theories appear during hot rolling of aluminum and other materials in commercial practice. Such problems stem from secondary stresses produced by the distribution of internal strains. Unfortunately, the distribution of internal strains is generally not known nor is the variation of the internal strain distribution known with respect to factors such as; work-roll diameter, reduction per pass, initial thickness of the work-piece, speed of rolling, front and back tension, nature of friction between the rolls and the material rolled, temperature field in the material, physical properties of the material, shape of the roll contour and the mill behavior under load.

It can be deduced from the above review of previous work that a three-dimensional strain distribution for ring upset forging or for hot-rolling has not been accomplished. The photoplastic techniques thus offer exciting investigative possibilities for determining the three-dimensional strain distribution in the field of deformation processing. The main purpose of this research was to employ the photoplastic techniques to analyze the three-dimensional strain distribution in upset forged rings and hot-rolled bars by using the 70:30 Laminac mixture which is suited for photomechanics studies beyond the elastic limit as described above. A better 
understanding of strain distributions may provide solutions to problems encountered in forming operations. An experimental analysis of the strain distribution in the compressed rings as a function of the initial geometry will provide data for comparison with theoretical predictions. Also, such data may reveal the optimum geometry of rings to be most consistent with assumptions employed when friction coefficients are calculated from ring-compression test data. 


\section{EXPERIMENTAL PROCEDURE}

Specimen Preparation

A mixture of $70 \%$ rigid Laminac 4116 and $30 \%$ flexible Laminac 4134 was blended and mixed thoroughly with $0.25 \%$ methyl ethyl ketone peroxide that served as the basic reactor, $0.10 \%$ cobalt napthanate accelerator, and $1 \%$ of styrene and wax molding additives. The mixture was cast into cylindrical aluminum molds (12 inches high with internal diameter of 3 . inches) whose inner surfaces had been sprayed with a mold release agent to enhance the removal of the cast after curing. The casts were allowed to cure partially by holding at room temperature for 24 hours. The partially cured blocks were then removed from the molds, hung in an oven for 24 hours for post-curing at temperatures from $160^{\circ} \mathrm{F}$ to $190^{\circ} \mathrm{F}$ and then cooled at a rate of $60^{\circ} \mathrm{F}$ per hour. In machining specimens from the cast blocks, care must be taken that stresses are not introduced as a result of clamping.

\section{Compression of Rings}

A Baldwin-Tate-Emery Universal Testing Machine modified to permit a ront.roll.led strain-rate was used for the ring rompression tests to determine the coefficient of friction of the Laminac mixture. The output of a displacement transducer model 7DCDT - 1000 was fed directly to a D.C. 
voltmeter that gives a voltage indication proportional to displacement. The signal was then fed to a Moseley Autograph high input impedance $X-Y$ plotter model $2 \mathrm{~A}$ on which the graph of the required voltage versus time has been plotted. By controling the cross-head speed of the machine, the pen on the $X-Y$ recorder could be made to follow the graph, thereby controlling the strain rate.

Rings of outside diameter 2.5 inches, height 0.5 inch and internal diameters of 1.625 inch, 1.000 inch and 0.625 inch were machined from a single cast of the $70 \%$ rigid- $30 \%$ flexible mixture of Laminac. Actually, 12 rings of each size were machined out. Three sets of four rings of the same geometry were compressed axially to reductions of 10, 20, 30 and $40 \%$ in height. Each of the three sets was compressed between platens of different roughness: smooth dies with a surface roughness of 10 microinches, rough dies with a surface roughness of 80 microinches, and lubricated smooth dies. A constant strain rate of $0.007 \mathrm{sec}^{-1}$ was employed in the compression of the rings since this strain rate simulated the strain rate used to roll the Laminac billets at $51^{\circ} \mathrm{C}$. Additionally, a ring of outside diameter 2.5 inches, inside diameter 0.625 and height 0.5 inch machined from the $70: 30$ Laminac mixture was compressed between smooth dies to an $8 \%$ reduction in height at which point the load was held for five minutes. This was for the purpose of comparing the 
strain distributions obtained when rings of the same geometry were compressed to a greater reduction but with the load removed immediately. The residual reductions after relaxation were similar for the two cases.

Slices were taken transversely through the thickness and circumferentially from the compressed 70:30 Laminac rings and studied photoplastically to determine the three dimensional strain distributions in the rings.

As a check on the validity of theoretical predictions, the coefficient of friction of aluminum was determined experimentally by the ring compression test. Seven aluminum rings of outside diameter 2.5 inches, inside diameter 1.0 inch and height 0.5 inch were compressed at $425^{\circ} \mathrm{C}$ on smooth dies to reductions in height of $10,15,20,30,40,50$ and $60 \%$. The temperature of $425^{\circ} \mathrm{C}$ corresponds to the middle of the commercial rolling temperature range for aluminum. A strain rate of $0.007 \mathrm{sec}^{-1}$ was employed.

\section{Roliing of the 70:30 Laminac Mixture}

After establishing the fact that the selected photoplastic material at $51^{\circ} \mathrm{C}$ fulfilled a majority of all necessary requirements for modelling, nineteen blocks with different thickness-to-width ratios were machined from a single Laminac cast. These blocks were rolled to various 
reductions in height by an electric motor-powered rolling mill which was completely enclosed by an insulated hotair chamber that maintained a constant temperature of $51^{\circ} \mathrm{C}$. The air was heated by a resistance element and continually circulated by means of a small blower. The electric powered roll drive system used a variable speed motor linked to a speed reducer gear box which was connected to a large gear by a link chain. The large gear engaged the drive gears on the rolls. The photoplastic billets were placed in the hot-air chamber at the mill entrance until they and the mill were equilibrated at the required temperature $\left(51 \pm 1^{\circ} \mathrm{C}\right)$. They were then pushed gently into the mill until the rolls began to grip.

The overall advantages of the rolling mill complex is that it offers the opportunity of controlling the rolling temperature within $\pm 1^{\circ} \mathrm{C}$, allows continuous variation of roll speed by a factor of 10 in the range compatible with the etrain rate requirements of the photoplastic material and it allows the friction to be varied by modifying the texture of the roll surface.

During rolling the speed was adjusted to correspond to the simulative strain-rate of $0.007 \mathrm{sec}^{-1}$ for aluminum. Correspondingly, the majority of blocks were rolled at 0.2 revolution per minute. Four blocks with different thicknessto-width ratios were also rolled to various reductions in 
thickness at a roll speed of 0.05 revolution per minute in order to determine the influence of roll speed on the strain distributions. Using photoplasticity techniques and assuming constant volume, it was possible to determine the three dimensional strain distributions on slices taken normal to the rolling direction for each of the blocks. The rolling conditions employed are given in Table 1. 


\section{RESULTS \\ Compression of the 70:30 Laminac Rings}

Table 2 shows the ring compression test data on smooth, rough and lubricated smooth platens. The final thicknesses were determined from an average of four measurements with a micrometer gage reading to 0.001 ins. The final internal diameters were also determined by averaging four measurements of internal diameters using a telescoping gage.

Transverse and circumferential slices were taken from each of the rings after compression as shown in Fig. 2. With the cartesian coordinates shown in Fig. 2, the difference between the algebraically larger and smaller inplane strains at any point in the transverse slice can be expressed as:

$$
\varepsilon_{r}-\varepsilon_{z}=\frac{N_{t} f}{h_{t}}
$$

where

$$
\begin{aligned}
\mathrm{N}_{t}= & \text { the fringe order at the point of interest on the } \\
& \text { slice } \\
\mathrm{h}_{t}= & \text { the thickness of the slice } \\
\mathrm{f}_{\varepsilon}= & \text { the material fringe constant. }
\end{aligned}
$$

At any point in the circumferential slice, the difference between the algebraically larger and smaller in-plane strains can be expressed as: 


$$
\varepsilon_{r}-\varepsilon_{\theta}=\frac{N_{c} f_{\varepsilon}}{h_{C}}
$$

$\mathrm{Eq} \cdot 2$

where

$$
\begin{aligned}
\mathrm{N}_{C}= & \text { the fringe order at the point of interest on the } \\
& \text { slice } \\
\mathrm{h}_{C}= & \text { the thickness of the slice } \\
f_{\varepsilon}= & \text { the material fringe constant. }
\end{aligned}
$$

In another investigation (34) the fringe constant for the 70:30 Laminac was found to be 0.004 frirge/inch.

A unique method has been employed in order to determine the fringe order, $N$, in both the transverse and circumferential slices taken from each of the compressed Laminac rings. Previous work (34) established that the 70:30 Laminac mixture from which these rings were machined was negatively birefringent. In order to find the exact fringe order, $\mathrm{N}$, in any of the slices, a diametrically loaded, stress-frozen disk made from Bakelite ERL 2774 which is positively birefringent was placed on the slice where fringe order information was needed. The fringe patterns were observed using white light with the polariscope. The stress-frozen disk was laid on the slice and oriented with its fringes parallel to those in the slice at the position where fringe order information was desired. The stressfrozen disk was translated back and forth in a direction 
perpendicular to the fringes until matching integral fringe orders in the slice and disk superposed. This condition produced an extinction which appeared as a black fringe. Thus, knowing the fringe order of the disk which corresponded to the extinction, the fringe order of the extinct fringe in the slice was obtained. In other words, fringe order one in the slice provided a black fringe at the order one position in the disk while all other fringe orders in the disk remained colored. This was also true for successively increasing fringe orders. Using this technique to determine the fringe order in either of the transverse or circumferential slice at any point, the successive full fringe orders at other points could be determined from the colored fringes of the slices.

The circumferential slice taken from the center of each of the compressed rings gave the difference between the larger and smaller in-plane strains only along the mid-section of the ring. from the inner radius to the outer radius (Eq. 1 ). Consequently, on the transverse slice the difference between the larger and smaller in-plane strains along the midsection (Eq. 2) had to be considered. A third equation involving the three strain components was obtained by assuming constancy of volume which gives:

$$
\varepsilon_{r}+\varepsilon_{z}+\varepsilon_{\theta}=0
$$


Therefore, the three strain components $\left(\varepsilon_{r}, \varepsilon_{\theta}\right.$ and $\left.\varepsilon_{z}\right)$ at positions where the circumferential and transverse slices intersected, could be determined by simultaneous solution of the three equations (Eqs. 1,2 and 3 ).

To assist in selecting the correct fringe order, $N$, either on the circumferential or transverse slice, darkfield isochromatic fringe patterns of the slices from each of the compressed rings were taken. The dark-field isochromatic fringe patterns of the slices taken from the rings with initial internal diameters of $1.625,1.00$ and 0.625 inch and compressed on smooth platens are shown in Fig. 3a. In Figures $3 b$ and $3 c$ are shown the dark-field isochromatic fringe patterns of the slices from the rings compressed on rough and lubricated smooth platens with the initial internal diameters cited directly above.

In order to determine $\mathrm{N}_{t}$ and $\mathrm{N}_{\mathrm{C}}$, the fringe orders at any particular point along the mid-section of the ring on the transverse and circumferential slices, a graph in which the fringe order versus the relative position $\frac{r-r_{0}}{R-r_{0}}$ was plotted. In this plot, $r$ is the distance of any full fringe order from the center of the compressed ring, $r_{0}$ is the inner radius of the ring after compression while $R$ is the final external radius of the compressed ring. For any relative position along the mid-section of the ring, the corresponding $\mathrm{N}_{t}$ and $\mathrm{N}_{c}$ were determined from the plot for each of the 
compressed rings. A typical plot of the fringe order versus the relative distance $\frac{r-r_{O}}{R-r_{O}}$ is presented in Fig. 4.

From this plot a spectrum of points was picked along the relative distance axis. 'Knowing the corresponding $N_{t}$ ' $\mathrm{N}_{c} ; \mathrm{h}_{t}, \mathrm{~h}_{c}$ and the value of $\mathrm{f}_{\varepsilon}(0.004$ fringe/inch), the three dimensional strain distributions at each selected point were determined. The three dimensional strain distributions from the inner radius to external radius of each of the compressed rings were plotted against the selected position points. These plots are shown in Figs. $5 a, 5 b$, and $5 c$ for the rings compressed on smooth, rough and lubricated smooth platens respectively. In cases where the initial reductions and consequent relaxed residual reductions were too small to produce a sufficient number of fringes, strain distributions were omitted.

Besides the limitation imposed by too few fringes in the lightly deformed rings, the maximum load output of the machine limited the highest initial reduction that could be attained. This situation was more prevalent when compressing rings with original internal diameters of 0.625 inch on rough platens. An initial reduction of only $30 \%$ could be attained on these rough platens at the maximum load capacity of the machine. 
Coefficient of Friction of the 70:30

Laminac Mixture

An attempt was made to use the Male-Cockcroft empirical analysis for determining the coefficient of friction under conditions of bulk plastic deformation. However, examination of their data showed that their formula was not correct. Based on their data, the empirical formula was corrected to the form:

$$
\Delta \mathrm{D}=\mathrm{m} \log _{10}\left(\frac{\mu}{0.055}\right)
$$

where $m$ is given by

$$
\ln \mathrm{m}=(0.044 \times 8 \text { Deformation })+\ln 6.6
$$

and

$\Delta \mathrm{D}=$ Percentage decrease in internal diameter of the ring. Their experiment was repeated as a check on the corrected formula. The decrease in internal diameter of an aluminum ring compressed at $425^{\circ} \mathrm{C}$ at a strain rate of $0.007 \mathrm{sec}^{-1}$ versus the percent deformation showed excellent agreement with the form of their plot as shown in Fig. 6 .

The geometric changes obtained in the compression of the 70:30 Laminac rings on platens with different surface characteristics, are given in Table 2. Plots of the decrease in internal diameter of the 70:30 Laminac rings versus the percent retained reduction are presented in Fig. 7 .

To evaluate the homogeneity of plastic deformation during 
the upsetting of various ring sizes on smooth, rough and lubricated smooth platens, graphs of the average strain components $\varepsilon_{z}$ (avg.); $\varepsilon_{r}$ (avg.), and $\varepsilon_{\theta}$ (avg.), along the mid-section of various rings were plotted against in $\frac{h_{0}}{h}$ in Fig. 8. The definition of the average strains can be illustrated using $\varepsilon_{z}$ (avg.); it is the sum of the $\varepsilon_{z}$ at the data points shown, for example, in Fig. 5 divided by the number of such data points. The dashed lines on each plot represent the appropriate strain component variation that would occur for homogeneous deformation.

As indicated earlier, the first satisfactory analysis of the compression of a flat ring was made by Avitzur (2) through an optimum upper hound mathematical solution. This was verified later by Hawkyard and Johnson (3) using a stress' analysis approach. In his theoretical treatment, Avitzur (2) developed the following mathematical relationships which can be used to determine the neutral radius, $R_{n}$, for a ring specimen under compression.

1) When $R_{n} \leq R_{i}$

$$
-\ln \left|\frac{\left.R_{i}\right)_{0}}{R_{0}} \frac{1+\sqrt{1+3\left(R_{0} / R_{n}\right)^{4}}}{1+\sqrt{1+3\left(R_{i} / R_{0}\right)^{4}\left(R_{o} / R_{n}\right)^{4}}}\right|=2\left(m \frac{R_{0}}{T}\right)\left(1-\frac{R_{i}}{R_{0}}\right)
$$


2) When $R_{i} \leq R_{n} \leq R_{0}$

$$
\left.-2\left(m \frac{R_{0}}{T}\right)\left(1+\frac{R_{i}}{R_{0}}-2 \frac{R_{n}}{R_{0}}\right)=\ln \mid \frac{R_{i}}{R_{0}}\right)^{2} \frac{1+\sqrt{1+3\left(R_{0} / R_{n}\right)^{4}}}{1+\sqrt{1+3\left(R_{i} / R_{0}\right)^{4}\left(R_{0} / R_{n}\right)^{4}}} \mid
$$

Eq. 5

where

$$
\begin{aligned}
\mathrm{R}_{\mathrm{n}} & =\text { Neutral radius } \\
\mathrm{m} & =\text { Shear factor } \\
\mathrm{R}_{i} & =\text { Internal radius } \\
\mathrm{R}_{0} & =\text { Original (initial) outer radius } \\
\mathrm{T} & =\text { Thickness }
\end{aligned}
$$

Avitzur (2) also proposed the following mathematical relationship to use for computing the neutral radius directly from experimental data:

$$
\left(\frac{R_{n}}{R_{0}}\right)^{2}=\frac{R_{i} / R_{0}-\Delta R_{i} / \Delta R_{0}}{R_{0} / R_{i}-\Delta R_{i} / \Delta R_{0}}
$$

$\mathrm{Eq} \cdot 6$

where

$$
\begin{aligned}
\Delta \mathrm{R}_{\mathrm{O}^{\prime}} \Delta \mathrm{R}_{i}= & \text { changes in the outer and inner radii } \\
& \text { respectively and the other symbols were } \\
& \text { defined above. }
\end{aligned}
$$

Ali three mathematical relationships (Eqs. 4, 5 and 6) were derived based on the assumption of a kinematically admissible pattern of deformation, that is, one satisfying 
the volume-constancy requirement and the geometrical boundary conditions (no bulging). Furthermore, it was assumed that planes normal to the axis of symmetry retain this property and their velocity varies linearly with their vertical distance from the origin which is the bottom center of the hollow disk. The assumption of a constant shear factor between platens and disk was also invoked.

Using Eq. 6, the neutral radius for each of the rings compressed on smooth, rough, and lubricated smooth platens was determined. Also, experimental positions of the neutral radii were obtained from the points where the $\varepsilon_{\theta}$ curves intersected the zero strain axis in. Figures $5 a, 5 b$, and $5 c$. These values can be compared with those computed from Eq. 6 (see Table 3 ).

Using the graphically determined or the computed values of $R_{n}$, the shear factor for each of the compressed rings was calculated from Eqs. 4 and 5. The shear factors, m, are presented in Table 3 .

The additional 70:30 Laminac ring of outside diameter 2.5 inches, inside diameter 0.625 and height 0.5 inch compressed between smooth platens to $8 \%$ reduction in height with load held for five minutes acquired identical patterns with another ring of the same geometry but with the load removed immediately. That identical fringe patterns resulted from both cases is shown by the dark-field isocromatic 
fringe patterns presented in Figs. 9a and 9b. The three dimensional strain distribution and the average strain components $\left[\varepsilon_{z}(\operatorname{avg}),. \varepsilon_{r}(\operatorname{avg}\right.$.$) and \varepsilon_{\theta}$ (avg.)] along the mid-section of the two rings are shown in Figs. 10a and $10 \mathrm{~b}$.

Rolling of the 70:30 Laminac Mixture

Three sets of slices were taken from each block that was rolled for photoplasticity studies; two transverse slices, slices 1 and 2 , three slices parallel to the rolling direction, slices 3, 4 and 5, and three slices perpendicular to the roll axis, slices 6,7 and 8 . The orientations and locations of these slices are shown in Fig. 11. For the $1 / 2$ and $1 / 4$ inch thick blocks, only slice 4 was taken from the set of slices parallel to the rolling direction due to the thinness of the blocks. Furthermore, only this slice can be machined conveniently from the block. Each slice was 0.125 inch thick and provided isochromatic and isoclinic (15) data on the strain field in the plane of the slice. The three sets of. slices thus provided information on the strain distributions in three orthogonal planes.

The Tardy. (15) method of compensation was used to determine the fringe orders in the planes of the slices. Knowing the fringe order $\mathrm{N}$, the thickness $\mathrm{h}$, and substituting 0.004 fringe/in. for the value of $f_{\varepsilon}$ ' the material fringe constant, the difference between the algebraically larger and smaller 
in-plane strains $\left(\varepsilon_{1}-\varepsilon_{2}=\frac{N E_{\varepsilon}}{h}\right.$ can be determined at any point in the slices. In terms of the cartesian coordinates ox, oy and $\mathrm{Oz}$ shown in Fig. 11, the difference between the in-plane strains in either slice 1 or 2 , are $\varepsilon_{\mathrm{x}}-\varepsilon_{\mathrm{y}}$; for any of the slices 3,4 and 5 , they are $\varepsilon_{z}-\varepsilon_{x}$, and for any of the slices 6,7 and 8 they are $\varepsilon_{z}-\varepsilon_{y}$. At any point of intersection of two sets of slices, it was possible to obtain two independent equations. By assuming constancy of volume, a third independent equation was obtained. The solution of these three independent equations provided the three dimensional strain distributions on slices taken normal to the rolling direction for each of the rolled blocks. The three dimensional strain distributions at 9 points for blocks with initial thickness of 1 inch and 3 points $(2,5$ and 8 ) for blocks with initial thickness of $1 / 4$ or $1 / 2$ inch were determined. The two dimensional views of slices 2 (slice taken normal to the rolling direction) and the corresponding intersection slices taken parallel and perpendicular to the roll axis are shown in Fig. 12. Points at which strains were determined are indicated in the figure. The three dimensional strain distributions on slices taken normal to the rolling direction for each of the rolled blocks are presented in Table 4.

Theoretical predictions of $\mathrm{Oh}$ and Kobayashi (13) indicate that. the amount of spread decreases. as initial width-tothickness ratio increases and increases with increasing reduction. To check the validity of these predictions, 
the strain at position 2, for each of the blocks with sizes $0.25 \times 2 \times 6$, inches and $0.25 \times 1 \times 6$ inches, was plotted versus initial percentage reduction and versus the residual percentage reduction as shown in Fig. 13. The residual reduction is that which remains when the block has relaxed completely after rolling. In order to determine the effect of geometry on the double bulging caused by nonuniform strain distributions, the average of each strain, $\varepsilon_{x^{\prime}} \varepsilon_{y}$ and $\varepsilon_{z}$ at positions $1,3,7$ and 9 for. the blocks with original thicknesses of 1 and 2 inches was plotted (Fig. 14) against the parameter, $\phi$, that combines the original thickness, $h_{0}$ ' the roll radius, $R$, and the fractional reduction, $\delta$, in the form $\phi=\frac{\mathrm{h}_{0}}{\sqrt{\mathrm{R} \delta}}$. The dashed lines in Fig. 14 join the difference of. the $\varepsilon_{x}$ average at positions $1,3,7$ and 9 and the $\varepsilon_{x}$ average at positions 2 and 8 . This was done to reveal the different behavior of lateral strains at the midwidth and at the edges. 


\section{DISCUSS ION \\ Upset Forging of 70:30 Laminac Rings}

As a result of recent ring upset forging research a relatively simple method has been developed for determining the coefficient of friction between die and workpiece under conditions simulating actual practice (1). Theoretical predictions for edge bulging during ring upsetting were given by Liu (37). Kobayashi (38) investigated the stress and strain histories at the equatorial free surface in simple upsetting of solid cylinders and rings of 1040 steel. His test methods were almost identical to those of Kudo and Aoi (39) in which the friction condition at the interface was controlled by using grooved dies and conical dies with and without lubrication. He derived stresses at the free surface from the measurements of strains.

In spite of these previous research efforts, the strain distribution within compressed rings has not been established: From the present research effort, threedimensional strain distributions were obtained for the midthickness planes of upset rings. The results were only qualitative because the visco-elastic photomechanic material used allowed the strain to relax with time. Methods of inhibiting relaxation, or for determining how the relaxation alters the strain distribution; must be established before 
quantitative results can be obtained.

Many phenomena observed during upset forging of the 70:30 Laminac rings agreed well with reported observations during upset forging of metallic rings. Two possible modes of deformation, depending on tool-workpiece interface friction conditions, have been predicted and demonstrated in ring upset forging $(37,40)$. The first mode, which is characterized by a convex outer edge and a concave inner edge, is favored when the friction between workpiece and tool is very low. All the 70:30 Laminac rings compressed between smooth platens lubricated with Molykote $\mathrm{Z}$, exhibited this mode of deformation during forging. Previous investigators $(37,40)$ claimed that the neutral radius, for this mode, was less than the inner radius of the rings. In the present investigation the neutral radius of 70:30 Laminac rings compressed between lubricated smooth platens did not behave this way consistently. For example, Fig. 5c shows that the neutral radius, taken as the position where $\varepsilon_{\theta}$ equals zero, is less than the inner radius of sample $\mathrm{L}-2$. Sample L-3 which had the same geometry and was forged under the same condition, but to a greater reduction, had a neutral radius greater than the inner radius of the ring. For an even higher reduction (Sample $\mathrm{L}-4$ ) the neutral radius was less than the inner radius. In samples $\mathrm{L}-6, \mathrm{~L}-7$ and $\mathrm{L}-8$ (original 
inner diameter of 1.000 inch), the neutral radius was always greater than the inner radius. For the rings with 0.625 inch original inner diameter sample L-10 had a neutral radius less than the inner radius of the rings. Two other samples with the same inner diameter (Samples L-11 and L-12) but given greater reductions had neutral radius positions greater than the inner radius. On the whole, the location of the neutral radius for the 70:30 Laminac rings forged between lubricated smooth platens was not consistent and did not agree with the prediction and observation of the earlier investigators $(37,40)$.

From the above discussion it is evident that the geometry and the percentage reduction (be it residual or initial pexcentage reduction) determined the location of the neutral radius for the $70: 30$ Laminac rings compressed between lubricated smooth platens.

The second mode of deformation, predicted and observed, is characterized by convex inner and outer edges. For this mode of deformation, the neutral radius falls between the inner and outer radii. All the 70:30 Laminac rings compressed on both the smooth and rough platens exhibited this mode of deformation.

Male and Cockcroft (1) pointed out earlier that measurements of the internal diameter of a compressed ring pro- 
vide a particularly sensitive means of determining the coefficient of friction, $\mu$. The internal diameter increases when $\mu$ is small and decreases when $\mu$ is large. This trend was observed in the compression of 70:30 Laminac rings on smooth, rough and lubricated smooth platens. However, as mentioned earlier, in case of lubricated smooth platens, only samples L-4 and L-8 exhibited an increase in internal diameter. An increase occurred at higher reductions only when the load was held for a short period of time. This may have been a reflection of the reduced relaxation that occurred when the load was maintained for a period of time. Despite the fact that the geometry of the aluminum ring compressed between smooth platens was quite different from the geometry employed for friction studies of aluminum by Male and cockcroft (I), excellent agreement regarding the form of the $\Delta D$ versus reduction curve (Fig. 6) was obtained even though they used a higher test temperature $\left(600^{\circ} \mathrm{C}\right)$. This similarity in the form of the curve shows that the coefficient of friction between the aluminum ring and the platens was constant during compression. However, the $\Delta D$ versus reduction curves for the 70:30 Laminac rings of similar geometry had greatly different forms compared to those obtained with metals in this investigation and by Male and cockcroft. The discrepancies, shown in Fig. 7, reveal that the coefficient of friction decreases as the percentage 
reduction increases. The Male-Cockcroft curves for metals are indicated by the dashed lines for different values of $\mu$. Besides the decreased barrelling of the 70:30 Laminac rings, relaxation probably affects the overall experimental results. The extent of this relaxation affect is not known. Based on these facts, it is not surprising that there is a general lack of correlation between the Male-cockcroft $\Delta \mathrm{D}$ versus reduction curves and those obtained with 70:30 Laminac rings. The first satisfactory analysis of the compression of a flat ring was made by Avitzur (2) through an optimum upper bound mathematical solution. Included in this analysis is the experimental determination of the neutral radius. To a certain degree, there is a very good correlation between the neutral radius determined from Avitzur's (2, Eq. 6) relationship and the value obtained graphically from the three dimensional strain distributions along the mid-section of the rings shown in Fig. $5 a, b, c$.

Strong evidence supporting the validity of the graphical determination of the neutral radius was provided fortuitously by sample s-4. In machining the transverse slice to a thickness of 0.045 inch, a circumferential crack became visible. This crack resulted in the separation of the circumferential slice into two pieces with separation occurring almost at the neutral radius evaluated graphically and by 
using Avitzur's relationship (Eq. 6). In addition to providing experimental evidence to back the theoretical prediction of the neutral radius position, sample $\mathrm{s}-4$ also confirmed that the neutral radius is actually the radial position where the radial velocity vanishes. In other words, there exists a cylindrical boundary at the neutral radius such that, on compression, the material outside the neutral radius is displaced outward and the material inside the neutral radius is displaced inwards.

In the mathematical analysis of ring compression carried out by Avitzur (2), a constant interfacial friction factor was assumed and barrelling was neglected. In other words, the effect of frictional stresses at the die/specimen interfaces was assumed to be transmitted uniformly throughout the specimen thickness thus simplifying conditions. Avitzur's (2) assumptions have been shown to be invalid for metals over all conditions of interfacial friction until the outside diameter to inside diameter to thickness ratio approaches $6: 3: 0.5$ as predicted from the experiments of Male and Depierre (41). A number of experimental curves analyzed theoretically by Male and Depierre (41) yielded values of $\mathrm{m}$ considerably in excess of unity. The values of the interfacial friction factor computed from Avitzur's relationship in the present investigation were sometimes in excess of unity. The values of $\mathrm{m}$ in Table 3 show that the interfacial friction 
factor, $m$, is not constant. However, for the samples compressed on lubricated smooth platens the majority of the $m$ values were less than unity. It was only for sample L-6 that $m$ was greater than one. For samples compressed on smooth or rough platens, the majority of computed m values were greater than one. It appears that, in general, Avitzur's theory for the interfacial friction factor leads to errors even for the Laminac mixture.

An analysis of the homogeneity of the plastic deformation occurring during the upsetting of 1040 steel rings was made by Kobayashi (38). He claimed that in the upsetting of the ring specimens, the displacements deviated greatly from those for homogeneous deformation even under lubricated conditions, thus causing the dimensional change of the inner surface to be sensitive to the friction conditions at the interface. Also, he pointed out that the more severe the frictional constraints the greater the strain path deviated from that for homogeneous deformation. For the three sets of ring geometries employed in the analysis of strain distribution in compressed rings, the circumferential strain $\left(\varepsilon_{\theta}\right)$, shown in Figs. $8 \mathrm{a}$ and $8 \mathrm{~b}$, deviates from the behavior expected for homogeneous deformation which is depicted by the dashed lines. Presumably this deviation is a result of barrelling or bulging. The deviation of $\varepsilon_{r}$ is less, as shown in Fig. 8c, when the platens and rings are lubricated. But, the axial 
and radial strains $\varepsilon_{z}$ and $\varepsilon_{r}$ obtained from rings compressed between smooth and rough platens deviate substantially more from homogeneous deformation as Figs. $8 \mathrm{a}$ and $8 \mathrm{~b}$ reveal. On the other hand, $\varepsilon_{z}$ and $\varepsilon_{r}$ values obtained from rings compressed between lubricated smooth platens show less deviation (Fig. 8c). Also, from Figs. $8 \mathrm{a}, \mathrm{b}$ and $c$, it is evident that both $\varepsilon_{z}$ and $\varepsilon_{r}$ increase as the percentage reduction increases but $\varepsilon_{\theta}$ values do not increase with reduction in all cases. Based on an in-depth study of the 70:30 Laminac mixture under compression, it became evident that holding the load at an initial reduction minimized the relaxation and thus lead to higher residual reduction after unloading. Compressing to a higher initial reduction with the load removed immediately, gave rise to a residual reduction which was nearly equal to that obtained when the load was held. The similarity exhibited by dark-field isocromatic fringe patterns in Figs. $9 a$ and $b$ for the ring with $8 \%$ reduction with the load held and the ring given $20 \%$ reduction with the load removed immediately can be correlated with the strain distribution resulting from their final measured residual reductions which are about equal. The average values of the radial strain, $\varepsilon_{r}$ (avg.) for the two rings were the same. Also point-by-point values of $\varepsilon_{r}$ along the mid-section of the two rings are equal. By holding the load for a period of time, a higher reduction is retained because the strain 
relaxation is reduced. An important observation worth noting is that the value of the average axial strain at the mid-thickness of the rings which were held under load for a short time was twice the value of the residual percentage reduction when rough and smooth platens were used. For rings compressed between lubricated smooth platens with the load held, the ratio of the average axial strain to residual percentage reduction was roughly one-to-one.

\section{Rolling of the 70:30 Laminac Mixture}

The effect of friction on shape change during rolling and, consequently on the three dimensional strain distribution in the block, is evident in the strain distributions of the 0.25 inch thick $x I$ inch wide and 0.25 inch thick $x 2$ inch wide blocks as shown in Table 4. At.an initial reduction of $7 \%$, there was no sidewise spread in either of the blocks, i.e., $\varepsilon_{x}$ was zero at all positions. At $14 q$ reduction $\varepsilon_{x}$ was greater than zero in the blocks only at positions 2 and 8 (edge positions). At center position $5, \varepsilon_{\mathrm{x}}$ remained zero. A different strain distribution was obtained when the two sizes of blocks were rolled to a $20 \%$ reduction. While $\varepsilon_{x}$ at the center of the two-inch wide block remained zero, it increased to 4.78 at the center of the one-inch wide block. All the $\varepsilon_{X}$ values computed at positions 2 and 8 for the oneinch wide blocks were greater than those computed for the 
two-inch wide blocks at the same relative positions. Thus it can be concluded that the roll pressure penetration was greater for the one-inch wide block than for the two-inch wide block. In other words, the friction effect was less for the one-inch wide blocks than for the two-inch wide blocks.

The plane-strain assumption upon which most of the existing rolling theories have been based was reconfirmed by the strain analysis of the 0.5 inch high $\times 2$ inch wide blocks which were rolled to 7 and $14 \%$ reductions in height. At $20 \%$ reduction, the plane-strain assumption no longer held for this particular size of block. While spread occurred at position 2, at position 8 on the opposite side, $\varepsilon_{x}$ was zero. A block of similar height but with a width of 1 inch, exhibited compressive strain at a reduction of 78 at positions 2 and 8 while at 148 reduction, the strain at the edges were zero and increased rapidly until at $20 \%$ reduction the block cracked.

The double-bulge phenomenon that has been observed during hot-rolling of aluminum billets in commercial practice was also observed in the rolling of 70:30 Laminac blocks with original heights of one inch when rolled at $51{ }^{\circ} \mathrm{C}$. As pointed out earlier, the three-dimensional strain distribution at nine points were evaluated on slice 2 taken parallel to the 
roll axis from the blocks which were originally 1 inch high. Considering the strains at positions 1,2 and 3 along one edge of the block and at positions 7,8 and 9 along the other edge, it is evident from the results presented in Table 4 that the values of $\varepsilon_{x}$ at positions 1, 3, 7 and 9 are greater than the $\varepsilon_{\mathrm{x}}$ value at either position 2 or 8 corresponding to the edge-center of the block. In other words, a clear picture of double-bulging was depicted by the values of $\varepsilon_{\mathrm{x}}$ computed along the edges of the block. Positions 1, 3 , 7 and 9 were located close to the rolls while positions 2 and 8 were at the center of the rolled billet. For the four blocks with original heights of 1 inch, irrespective of the width, the values of $\varepsilon_{x}$ through the thickness at positions 4, 5 and 6 acquired the same profile for all the blocks; $\varepsilon_{x}$ was maximum at the point close to one roll but decreased in value towards the billet center.

The influence of the block geometry on double-bulge formation during hot-rolling is clearly demonstrated by Fig. 14 where the average of each of the strains at positions 1 , 3, 7 and 9 is plotted against the parameter $\phi$. The difference between the average $\varepsilon_{x}$ values at positions $1,3,7$ and 9 and those at positions 2 and 8 , shown by the dashed lines, reflects the extent of double-bulging at various reductions. It is evident that double-bulging was less in 
the one-inch wide block than in the two-inch wide block. This is revealed by the difference between $\varepsilon_{\mathrm{x}}$ averaged over positions $1,3,7,9$ and $\varepsilon_{x}$ averaged over positions 2 and 8 . For the two one-inch wide blocks rolled to various initial percentage reductions in height, the value of the difference between $\varepsilon_{\mathrm{x}}$ averaged over positions $1,3,7,9$ and $\varepsilon_{\mathrm{x}}$ averaged over positions 2 and 8 , is equal to $\varepsilon_{x}$ averaged over positions $1,3,7$ and 9 at a lower reduction. $\Delta t \cdot a$ higher reduction, the $\varepsilon_{\mathrm{x}}$ value averaged over positions 1,3 , 7 and 9 was close to being equal to the difference between $\varepsilon_{\mathrm{X}}$ averaged over positions $1,3,7,9$ and $\varepsilon_{\mathrm{x}}$ averaged over positions 2 and 8 . For the two two-inch wide blocks rolled to various initial percentage reductions in height, the value of the difference between $\varepsilon_{\dot{x}}$ averaged over positions 1, 3, 7, 9 and $\varepsilon_{\mathrm{x}}$ averaged over positions 2 and 8 was equal to $\varepsilon_{\mathrm{x}}$ averaged over positions $1,3,7$ and 9 only at lower initial reduction. At higher initial percentage reduction in height, the difference in $\varepsilon_{\mathrm{x}}$ averaged over positions $1,3,7,9$ and $\varepsilon_{\mathrm{x}}$ averaged over positions 2 and 8 , was not at all close to $\varepsilon_{\mathrm{x}}$ averaged over positions $1,3,7$ and 9 . From the above discussions, it is evident that the chances of double-bulge formation occurring in the two-inch wide 70:30 Laminac block when rolled to higher percentage reductions in height, are greater than for the one-inch wide block. The effect of roll speed employed in the rolling of the 
70:30 Laminac mixture was clearly demonstrated by the $0.5 \mathrm{x}$ $1 \times 6$ inch and the $0.5 \times 2 \times 6$ inch blocks rolled at speeds of 0.2 RPM and 0.05 RPM. When $0.5 \times 1 \times 6$ inch blocks were rolled to a reduction of $14 \%$ at roll speeds of 0.2 and 0.05 RPM the transverse spread was uniform on both edges as revealed by the fact that $\varepsilon_{x}$ values were equal at positions 2 and 8 (Table 5). Furthermore, the $\varepsilon_{x}$ values at positions 2, 5 and 8 were greater when the roll speed was 0.05 RPM than when the roll speed was 0.2 RPM. With another set of $0.5 \mathrm{x}$ $1 \times 6$ inch blocks rolled to a reduction of 5\%, the spread at positions 2 and 8 were equal only at a roll speed of 0.2 RPM. A plane-strain condition was attained when a $0.5 \times 2 \times$ 6 inch block was rolled at 0.2 RPM to reductions of $7 \%$ and 14\%. For similar blocks given the same reductions but at a roll speed of 0.05 RPM, a different spread pattern resulted. $\varepsilon_{\mathrm{x}}$ was compressive on one edge but tensile on the other edge.

From their experimental results concerning lateral spread in the rolling of lead, Chitkara and Johnson (14) found that the ratio of the final width to the original width increased with increasing reduction. Theoretical solution of this claim was given by Oh and Kobayashi (13) using extremum principles for rigid perfectly plastic materials. This trend was also predicted for steckel rolling by Hill's (5) analysis. The plot of $\varepsilon_{\mathrm{x}}$ values at the edge of the rolled 
70:30 Laminac blocks versus percentage reduction also followed this trend as shown graphically in Fig. 13 .

As indicated earlier in the Introduction, photoplastiçity has been used extensively for the past few decades as a unique technique for solving complicated engineering problems. A number of successes have been reported in the literature regarding the use of photoplasticity as a tool for determining stresses or strains in machine complexes. One significant fact which has not been given special attention is the extent to which the visco-elastic nature of most of the photomechanic materials influences the distribution of either. stress or strain.

Based on the present research, the 70:30 Laminac mixture is visco-elastic and the strain relaxes with time. Despite the fact that the neutral radius computed using Avitzur's (2) mathematical solutions for compressed rings agrees approximately with the one obtained from the $\varepsilon_{\theta}=0$ intercept of the three dimensional strain distribution along the midsection of the rings and, despite the fact that the increase in spread in the rolled 70:30 Laminac blocks increases with reduction as predicted by theory, it would be erroneous to conclude at this time that the three dimensional strain distributions for various ring and block geometries under various percentage reductions is quantitative without giving due consideration to the influence of relaxation on the 
distributions. A theory based on the visco-elastic properties of the photomechanic materials is worth pursuing. Such a theory will further enhance the validity of the strains evaluated by photoplasticity techniques.

Based on the results obtained from this research, the 70:30 Laminac mixture shows some trends in characteristics which have been established for metals. However, studies should be conducted to learn more about the structural properties of this mixture before the mixture can be claimed to be a good simulating material or before photoplasticity itself can be claimed a good technique to be used in analyzing strains from hot forming processes. Nevertheless, for the first time, a semi-quantitative three-dimensional strain distribution has been obtained experimentally for the midsection of a ring. Future research should be directed toward finding the variation of the three dimensional strain distribution over the thickness of the ring and also in the rolling direction for rolled billets. This may involve compressing thicker rings and rolling longer blocks which would permit more slices from either compressed rings or from rolled blocks to be taken for photoplasticity strain analyses. 


\section{SUMMARY}

Photoplasticity techniques have been employed to determine the three-dimensional strain distribution along the midsection in rings of various geometries under uniaxial compression and blocks of various sizes rolled to various reductions in height. A photomechanic material called Laminac has been used in the analysis of strains in both compressed rings and rolled blocks. Specifically, a 70\% rigid Laminac mixed with $30 \%$ flexible Laminac polyester resins which, at $51{ }^{\circ} \mathrm{C}$, provides a stress-strain curve that exhibits little or no strain hardening and which simulates, at least in the first approximation, the characteristics of aluminum when it is deformed at $425^{\circ} \mathrm{C}$, was used in the strain analysis.

A good correlation was found between the neutral radius determined graphically from the three-dimensional strain distribution along the mid-section of the ring plotted against the relative distance $\frac{r-r_{0}}{R-r_{0}}$, and the neutral radius determined using Avitzur's (2) mathematical solutions for compressed rings. However, as has been indicated for metals as well, the interfacial friction factor $m$ determined by another Avitzur's relationship applied to the 70:30 Laminac rings was found, in certain instances, to be in excess of unity. This tends to invalidate his theoretical solutions for determining the interfacial friction factor, $m$. 
Based on the three-dimensional strain distribution on the slice taken parallel to the roll axis, the ratio of the final width to the original width (which is equivalent to $\varepsilon_{x}$ at the edge of the rolled block) increased with reduction thereby supporting the theoretical prediction of $\mathrm{on}$ and Kobayashi (13) for spread during rolling. Double-bulging was found to be less in one-inch wide blocks than in two-inch wide blocks. Uniform spread on both edges of the block of this size was found to exist at higher reductions either at a roll speed of 0.2 RPM or 0.05 RPM. Plane-strain was found to exist only when the two inch wide blocks were rolled at 0.2 RPM either at lower or higher percentage reductions. The viscoelastic property of the 70:30 Laminac mixture still stands as a major problem in reaching a quantitative strain distribution in either the compressed rings or the rolled blocks. 


\section{REFERENCES}

1. Male, A. T., and M. G. Cockcroft. "A Method for the Determination of the Coefficient of Friction of Metals Under Condition of Bulk Plastic Deformation." Journal of the Institute of Metals 93 (1964), 38-46.

2. Avitzur, B. "Forging of Hollow Discs." Israel Journal of Technology, 2, No. 3 (1964), 295-304.

3. Hawkyard, J. B., and W. Johnson. "An Analysis of the Changes in Geometry of a Short Hollow Cylinder During Axial Compression." International Journal of Mechanical Sciences 9 (1967), 163-182.

4. Van Sant, O. J. "Mathematical Analysis for Axial Compression of a Flat Ring." Journal of the Institute of Metals 95 (1967), 125-127.

5. Hill, R. A. "General Method of Analysis for MetalWorking Processes." Journal of the Mechanics and Physics of Solids 11 (1963), 305-326.

6. Lahoti, G. D., and Shiro Kobayashi. "On Hill's General Method of Analysis for Metal-Working Processes." International Journal of Mechanical Sciences 16 (1974), $521-540$.

7. El-Waziri, A. H. "An Up-to-Date Examination of Rolling Theory." Iron and Steel Engineer 40 (October, 1963), 73-80.

8. Ei-Kalay, A. K. E. H. A. and L. G. N. Sparling. "Factors Affecting Friction and their Effect Upon Load, Torque and Spread in Hot Flat Rolling." Journal of the Iron and Steel Institute 206 (Feb. 1968), 152-163.

9. Helmi, A., and J. M. Alexander. "Geometric Factors Affecting Spread in Hot Flat Rolling of steel." Journal of the Iron and Steel Institute 206 (Nov. 1968), 11101117 .

10. Beese, J. A. "Ratio of Lateral Strain to Thickness Strain During Hot Rolling of Steel Slabs." Journal of the Iron and Steel Institute 210 (June 1972), 433436 . 
11. Averbach, B. L. "Plastic Deformation in the Rolling Process." Journal of Metals, Transactions AIME 188 (Jan. 1950), 150-155.

12. Orowan, E. "The Calculation of Roll Pressure in Hot and Cold Flat Rolling." Proceedings Institute of Mechanical Engineers 150, (1943), 140-167.

13. Oh, S. I., and Shiro Kobayashi. "An Approximate Method For a Three-Dimensional Analysis of Rolling." International Journal of Mechanical Sciences 17 (1975), 293-305.

14. Chitkara, N. R., and W. Johnson. "Some Experimental Results Concerning Spread in the Rolling of Lead." Journal of Basic Engineering 88, (June 1966), 489-499.

15. Dally, J. W., and W. F. Riley. Experimental Stress Analysis. New York: McGraw-Hill Book Co., 1965.

16. Durelli, A. J., and W. F. Riley. Introduction to Photomechanics. Englewood Cliffs, N.J.: Prentice-Hall, Inc., 1965.

17. Hetenyi, M. "A Study in Photoplasticity." U.S. Natl. Congress of App. Mech. Proc. I (1952), 499-502.

18. Fried, B., and N. H. Shoup. "A Study in Photoplasticity." U.S. Natl. Congress of App. Mech. Proc. 2 (1954), 477483 .

19. Brill, W. A. "Basic Studies in Photoplasticity." Ph.D. Thesis, Stanford, Cal., 1965.

20. Fried, B. "Some Observations on Photoelastic Materials Stressed Beyond the Elastic Limit." Proceedings of the S.E.S.A. 8(2), (1951), 143-148.

21. Frocht, M. M., and F. A. Thomson. "Studies in Photoplasticity." Proc. U.S. Natl. Cong. Appl. Mech. 3 $(1958), 533-540$.

22. Frocht, M. M., and Y. F. Cheng. "An Experimental Study of the Laws of Double Refraction in the Plastic State in Cellulose Nitrate-Foundations for Three-Dimensional Photoplasticity." Pages 195-216 in M. M. Frocht, ed. Photoelasticity: Proc. of Int. Symposium on Photoelasticity, 1961. New York: Pergamon Press, 1963. 
23. Mönch, E., and R. Loreck. "A Study of the Accuracy and Limits of Application of Plane Photoplastic Experiments." Pages 169-184 in E. Mönch, ed. Photoelasticity Proc. of Int. Symposium on Photoelasticity, 1961. New York: Pergamon Press, 1963.

24. Ito, K. "Studies on Photoelasto-plastic Mechanics." Journal of the Science Research Institute, Tokyo 50 (1956), 19-28.

25. Gurtman, G. A.; W. C. Jenkins, and T. K. Tung. "Characterization of a Birefringent Material for Use in Photoelasto-Plasticity." Douglas Rep. SM-47796, Jan. 1965.

26. Brinson, H. F. "An Interpretation of Inelastic Birefringence." Experimental Mechanics. 11 (Oct. 1971), 467-471.

27. Whitfield, J. K. "Characterization of Polycarbonate as a Photoelasto-Plastic Material." Ph.D. Thesis, Virginia Polytechnic Institute, 1969.

28. Loreck, R. "Untersuchung von PolyestergieBharzen und anderen Kunststoffen auf ihre Eignung als photoplastisches Modellmaterial." Kunststoffe 52. (1962), 139-143.

29. Dally, J. W., and A. Mulc. "Polycarbonate as a Model Material for Three-Dimensional Photoplasticity." Journal of Applied Mechanics Transactions of the ASME 40; Series E, No. 2 (June 1973), 600-605.

30. Durelli, A. J., and C. A. Sciammarella. "Elastoplastic Stress and Strain Distribution in a Finite Plate with a Circular Hole Subjected to Undimensional Load." J. of Applied Mech: 30 (March 1963), 115-121.

31. Morris, D. H., and W. F. Riley. "A Photomechanics Material for Elasto-plastic Stress Analysis." Expt1. Mech. 12 (1972), 10, 488-453.

32. Ohashi, Yoshio; and Nishitani Tadashi. "Effects of Front Tension on Strip Rolling Analyzed by Photorheological Method." Japan Society of Mechanical Engineers Bulletin, 14, NO. 76 (1971), 1043-1049.

33. Burger, C. P., A. K. Oyinlola, and T. E. Scott. "Full Field Strain Distributions in Hot Rolled Billets by simulation." . To be published in Metals. Engineering Quarterly, ca. 1976. 
34. Koenig, L. N. "Photoplasticity in the Hot Forming of Metals," M.S. Thesis, Iowa State University, 1976.

35. Zachary, L. W. and W. F. Riley. "Photomechanics Methods for Inelastic Stress Analysis." Final Report. U.S. Army Research Office DAHC-40-74-9-0105 (March 1976).

36. Ramberg, W., and W. R. Osgood. "Description of Stress-Strain Curves by Three Parameters." U.S. Natl. Advisory Committee for Aeronautics, Tech. Note 902 , 1943.

37. Liu, J. Y. "An Analysis of the Forging of a Flat Ring." ASME Paper No. 70-WA/Prod-28, 1970.

38. Kobayashi, Shiro. "Deformation Characteristics and Ductile Fracture of 1040 Steel in Simple Upsetting of Solid Cylinders and Rings." Journal of Engineering for Industry, Trans. ASME, Series B, 92, No. 2 (May 1970), 391-399.

39. Kudo, H., and A. Aoi. "Effect of Compression Test Condition Upon Fracturing of Medium Carbon-Steel-Study on Cold-Forgeability Test Part II." Journal of Japan Society of Technology in Plasticity 8, (1967), 17-27.

40. Depierre, V., F. Gurney, and A. T. Male. "Mathematical Calibration of the Ring Test with Bulge Formation." Technical Report AFML-TR-72-37, March 1972.

41. Male, A.T., and V. Depierre. "The Validity of Mathematical Solutions for Determining Friction from the Ring Compression Test." Journal of Lubrication Technology 93, No. 3 (July 1970), 389-397. 


\section{ACKNOWLEDGMENTS}

It is a valuable experience gained by working under Dr. T. E. Scott, my major professor, to whom I am indebted for many valuable discussions regarding this research. The understanding, thoughtfulness and concerns displayed by him while under him as a graduate student are gratefully appreciated. Certain ideas and studies incorporated in this research originated in personal discussions with Dr. C. P. Burger and Professor W. F. Riley of the Department of Engineering Science and Mechanics. For this, I wish to express my gratitude to them. The financial assistance of the National Science Foundation and the facilities provided by both the U.S. Energy Research and Development Administration and Engineering Research Institute at Iowa State University are gratefully acknowledged. 
APPENDIX A: TABLES 
Table 1. Rolling conditions of the 70:30 Laminac blocks at $51^{\circ} \mathrm{C}$

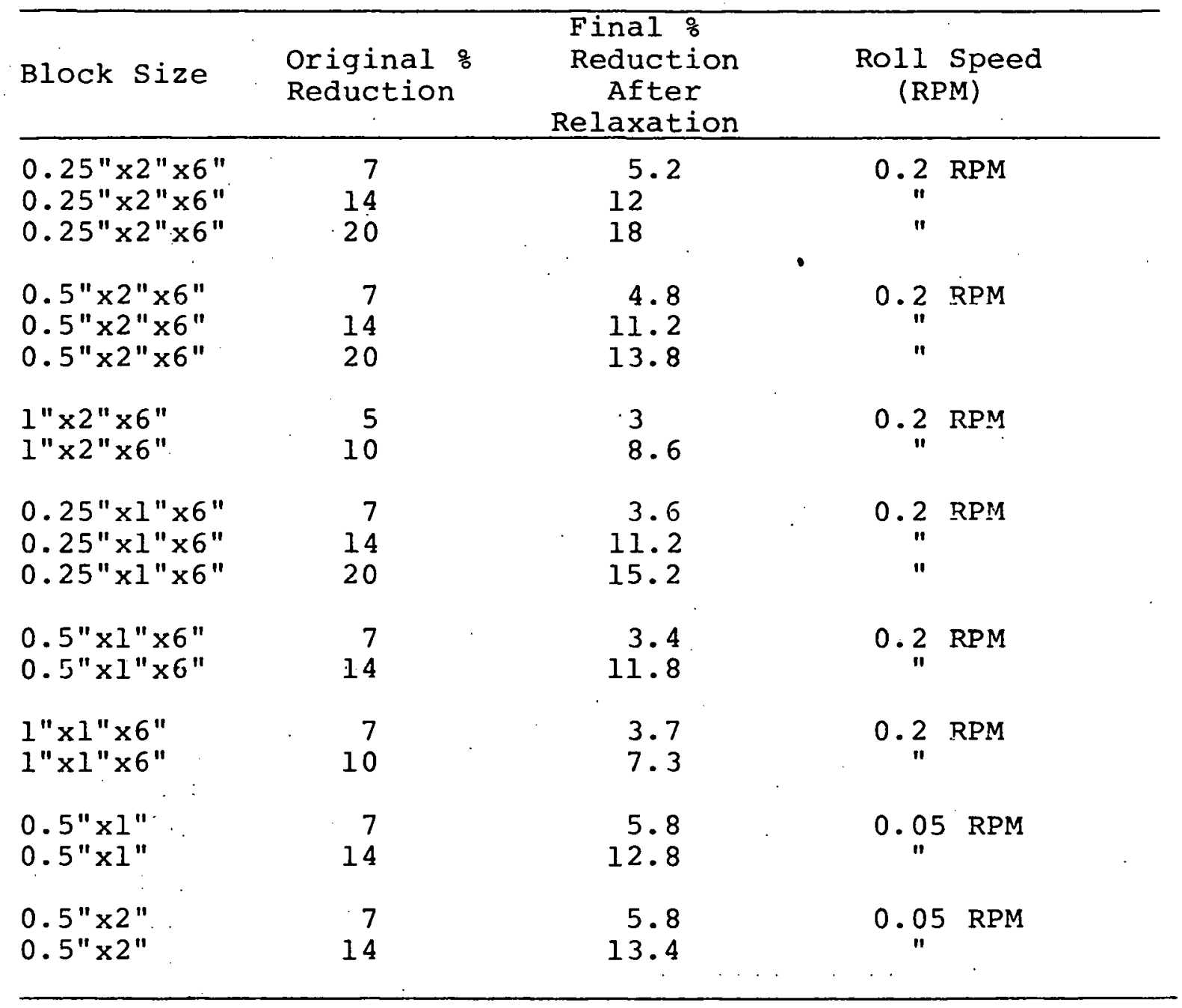


Table 2. Ring compression test data

\begin{tabular}{|c|c|c|c|c|c|c|c|c|}
\hline Sample & $\begin{array}{l}\text { O.D. } \\
\text { (ins.) }\end{array}$ & $\begin{array}{l}\mathrm{H}_{\circ} \\
\text { (ins.). }\end{array}$ & ${ }_{\text {(izs.) }}^{\mathrm{H}_{\mathrm{f}}}$ & $\begin{array}{c}\text { Initial } \\
\text { Reduction } \\
\text { \% }\end{array}$ & $\begin{array}{l}\text { Residual } \\
\text { Reduction } \\
\frac{q}{\delta}\end{array}$ & $\begin{array}{c}I D_{0} \\
\text { (ins.) }\end{array}$ & $\begin{array}{c}I D_{f} \\
\text { (ins.) }\end{array}$ & $\begin{array}{c}\Delta \mathrm{D} \\
8\end{array}$ \\
\hline$s-1^{b}$ & 2.5 & 0.5 & 0.484 & 10 & 3.2 & 1.625 & 1.595 & 1.85 \\
\hline$s-2$ & $"$ & $"$ & 0.468 & 20 & 6.4 & $"$ & 1.576 & 3.02 \\
\hline$s-3$ & $"$ & $"$ & 0.436 & 30 & 12.8 & $"$ & 1.550 & 4.62 \\
\hline$s-4$ & $"$ & $"$ & 0.110 & 45 & 18 & $"$ & 1.542 & 5.11 \\
\hline$s-5$ & 2.5 & 0.5 & .488 & 10 & 2.4 & 1.0 & 0.998 & 0.20 \\
\hline$s-6$ & $"$ & $"$ & 0.472 & 20 & 5.6 & $"$ & 0.933 & 6.70 \\
\hline$s-7$ & $"$ & $"$ & 0.450 & 30 & 10 & $"$ & 0.889 & 11.10 \\
\hline$s-8$ & $"$ & $"$ & 0.423 & 40 & 15.4 & $"$ & 0.862 & 13.8 \\
\hline$s-9$ & 2.5 & 0.5 & 0.481 & 20 & 3.8 & 0.625 & 0.567 & 9.28 \\
\hline$s-10$ & $"$ & $"$ & 0.466 & $12^{C}$ & 6.8 & $"$ & 0.530 & 15.20 \\
\hline$s-11$ & $"$ & $"$ & 0.450 & 20 & 10 & $"$ & 0.513 & 17.92 \\
\hline$s-12$ & $"$ & $1 "$ & 0.432 & 30 & 13.6 & $"$ & 0.506 & 19.04 \\
\hline
\end{tabular}

${ }^{a_{O . D .}}=$ Initial outside diameter of the ring; $\mathrm{H}_{\mathrm{O}}=$ original height of the ring; $\mathrm{H}_{\mathrm{f}}=\mathrm{Final}$ height $\mathrm{O}=$ the ring; $\mathrm{I} \mathrm{D}_{\mathrm{O}}=$ Initial internal diameter of the ring; $I D_{F}=$ Final internal diameter of the ring; $\Delta D=$ Percentage decrease in internal diameter of the ring.

$\mathrm{b}_{\text {Smooth platens. }}$

${ }^{C}$ Ring compression wi=h load held for short period of time. 
Table 2 (Continued)

\begin{tabular}{|c|c|c|c|c|c|c|c|c|c|}
\hline Sample & $\begin{array}{l}\text { O.D. } \\
\text { (ins.) }\end{array}$ & $\begin{array}{l}\mathrm{H}_{\mathrm{O}} \\
\text { (ins.) }\end{array}$ & $\begin{array}{l}{ }^{i n} \mathrm{f} \\
\text { (ins.) }\end{array}$ & $\begin{array}{l}\text { Initial } \\
\text { Reduction } \\
{ }_{\%}\end{array}$ & $\begin{array}{c}\text { Residual } \\
\text { Reduction } \\
\frac{a}{0}\end{array}$ & $\begin{array}{l}I D_{0} \\
(\text { ins.) }\end{array}$ & $\begin{array}{c}I D_{f} \\
\text { (ins.) }\end{array}$ & $\begin{array}{c}\Delta \mathrm{D} \\
8\end{array}$ & \\
\hline$R-1^{d}$ & 2.5 & 0.5 & 0.490 & 10 & 2 & 1.625 & 1.588 & 2.28 & \\
\hline$R-2$ & $"$ & $"$ & 0.463 & 20 & 7.4 & $"$ & 1.575 & 3.08 & \\
\hline$R-3$ & $"$ & $"$ & 0.455 & 30 & 9 & $"$ & 1.557 & 4.18 & \\
\hline$R-4$ & . & $"$ & 0.416 & $35^{C}$ & 16.8 & $"$ & 1.539 & 5.29 & \\
\hline$R-5$ & 2.5 & 0.5 & 0.487 & 10 & 2.6 & $1.00^{\circ}$ & 0.966 & 3.4 & \\
\hline$R-6$ & - & $"$ & 0.461 & 20 & 7.8 & " " & 0.911 & 8.9 & \\
\hline$R-7$ & " & $"$ & 0.433 & 30 & 13.4 & $"$ & 0.868 & 13.2 & \\
\hline$R-8$ & $"$ & $"$ & 0.431 & $40^{\circ}$ & 13.8 & $"$ & 0.876 & 12.4 & \\
\hline$R-9$ & 2.5 & 0.5 & 0.491 & 10 & 1.8 & 0.625 & 0.591 & 5.44 & \\
\hline$R-10$ & $"$ & $"$ & 0.450 & 30 & 10 & $"$ & 0.504 & 19.36 & \\
\hline$R-11$ & $\therefore 1$ & $"$ & 0.449 & $30^{c}$ & 10.5 & $"$ & 0.472 & 24.48 & \\
\hline
\end{tabular}


Table 2 (Continued)

\begin{tabular}{|c|c|c|c|c|c|c|c|c|}
\hline Sample & $\begin{array}{l}\text { O.D. } \\
\text { (ins.) }\end{array}$ & $\begin{array}{l}\mathrm{H}_{\mathrm{O}} \\
\text { (ins.) }\end{array}$ & $\stackrel{{ }_{f}}{\text { (ins.) }}$ & $\begin{array}{c}\text { Initial } \\
\text { Reduction } \\
q\end{array}$ & $\begin{array}{l}\text { Residual } \\
\text { Reduction } \\
\quad \frac{8}{8}\end{array}$ & $\begin{array}{c}I D_{O} \\
\text { (ins.) }\end{array}$ & $\begin{array}{l}I D_{f} \\
\text { (ins.) }\end{array}$ & $\begin{array}{l}\Delta \mathrm{D} \\
8\end{array}$ \\
\hline$L-1^{e}$ & 2.5 & 0.5 & 0.486 & 10 & 2.8 & 1.625 & 1.609 & 0.985 \\
\hline$L-2$ & $"$ & $"$ & 0.467 & 20 & 6.6 & $"$ & 1.604 & 1.29 \\
\hline$L-3$ & $"$ & $"$ & 0.453 & 30 & 9.4 & $"$ & 1.588 & 2.28 \\
\hline$L-4$ & $"$ & " & 0.391 & $45^{\dot{C}}$ & 21.8 & $"$ & 1.657 & -1.97 \\
\hline$L-5$ & $"$ & $"$ & 0.490 & 10 & 2 & 1.00 & 0.984 & 1.60 \\
\hline$L-6$ & $"$ & $"$ & 0.467 & 20 & 6.6 & $"$ & 0.970 & 3.00 \\
\hline$L-7$ & $"$ & $"$ & 0.448 & 30 & 10.4 & $"$ & 0.964 & 3.60 \\
\hline$L-8$ & $"$ & $"$ & 0.371 & $40^{\mathrm{C}}$ & 25.8 & $"$ & 1.004 & -0.4 \\
\hline $\mathrm{L}-9$ & $"$ & $"$ & 0.496 & 10 & 0.8 & 0.626 & 0.615 & 1.60 \\
\hline $\mathrm{L}-10$ & $"$ & $"$ & 0.476 & 20 & 4.8 & $"$ & 0.597 & 4.48 \\
\hline$L-11$ & $"$ & $"$ & 0.451 & 30 & 9.8 & $"$ & 0.585 & 6.40 \\
\hline$L-12$ & $"$ & $"$ & 0.370 & 40 & 26 & $"$ & 0.591 & 5.4 \\
\hline
\end{tabular}

ELubricated smooth platens. 
Table 3. Dimensional changes in the upset forging of $70: 30$ Laminac rings at $51^{\circ} \mathrm{C}$

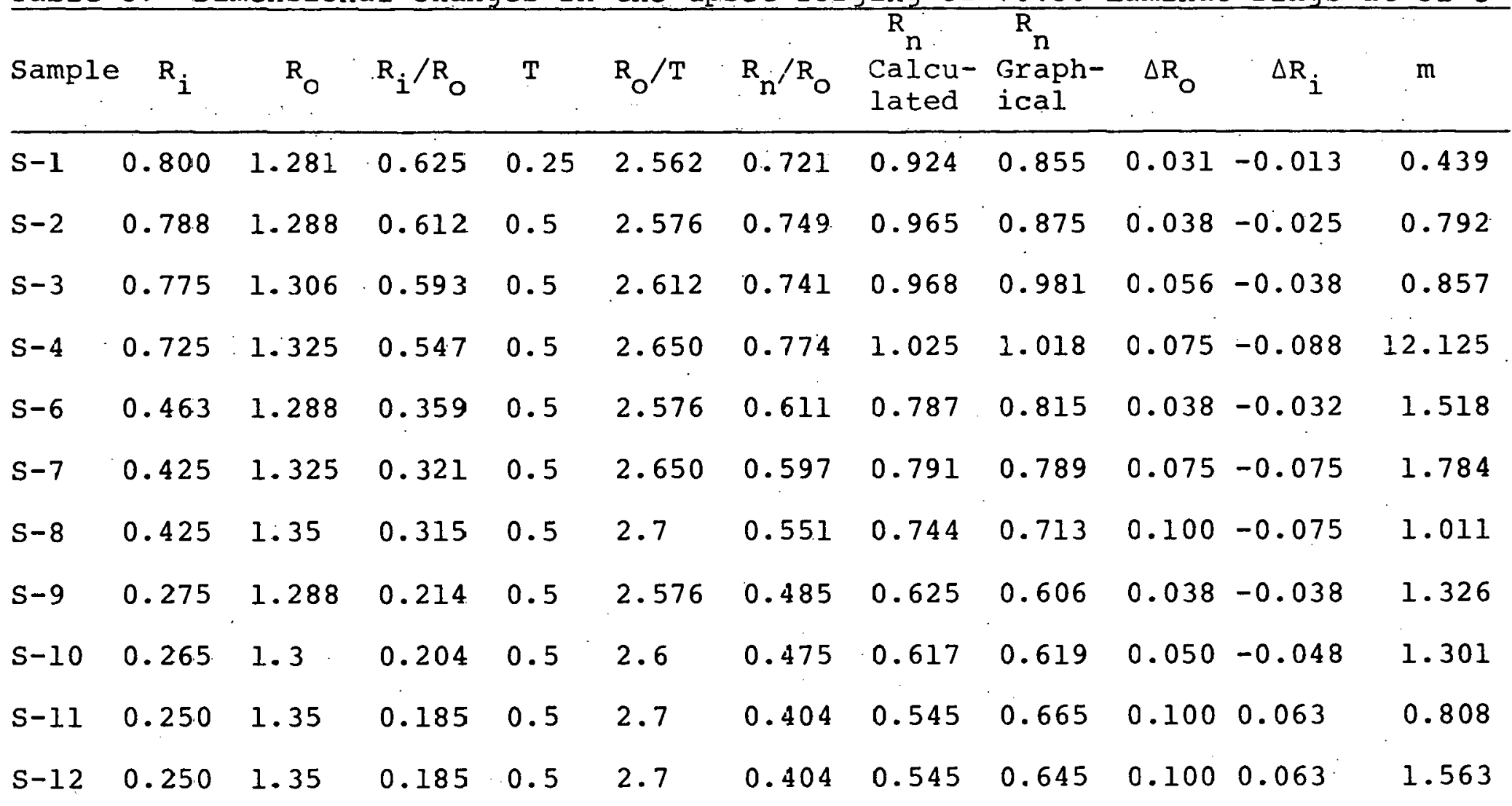


Table 3 (Continued)

\begin{tabular}{|c|c|c|c|c|c|c|c|c|c|c|c|}
\hline Sample & $\mathbf{R}_{\mathbf{i}}$ & $R_{0}$ & $R_{i} / R_{0}$ & $\mathrm{~T}$ & $\mathrm{R}_{\mathrm{O}} / \mathrm{T}$. & $R_{n} / R_{0}$ & $\begin{array}{l}\mathrm{R}_{\mathrm{n}} \\
\text { Calcu- } \\
\text { lated }\end{array}$ & $\begin{array}{l}\mathrm{R}_{\mathrm{n}} \\
\text { Graph- } \\
\text { ical }\end{array}$ & $\Delta R_{0}$ & $\Delta R_{i}$ & $\mathrm{~m}$ \\
\hline$R-1$ & 0.800 & 1.275 & 0.627 & 0.5 & 2.550 & 0.736 & 0.938 & 1.150 & 0.025 & 0.013 & 0.533 \\
\hline $\mathrm{R}-2$ & 0.788 & 1.300 & 0.606 & 0.5 & 2.600 & 0.690 & 0.892 & 1.125 & 0.050 & 0.025 & 0.358 \\
\hline$R-3$ & 0.775 & 1.300 & 0.596 & 0.5 & $2.600^{\circ}$ & 0.753 & 0.979 & 1.139 & 0.050 & 0.038 & 1.077 \\
\hline$R-4$ & 0.750 & 1.313 & 0.571 & 0.5 & 2.626 & 0.768 & 1.007 & 1.168 & 0.063 & 0.063 & 3.139 \\
\hline$R-7$ & $0 . \leqslant 38$ & 1.313 & 0.334 & 0.5 & 2.626 & 0.600 & 0.788 & 0.907 & 0.063 & 0.062 & 1.663 \\
\hline$R-8$ & 0.425 & 1.325 & 0.321 & 0.5 & 2.650 & 0.592 & 0.791 & 0.871 & 0.075 & 0.075 & 1.849 \\
\hline$R-10$ & 0.250 & 1.300 & 0.192 & 0.5 & 2.600 & 0.515 & 0.670 & 0.658 & 0.050 & 0.063 & 2.514 \\
\hline$R-11$ & 0.238 & 1.325 & 0.180 & 0.5 & 2.650 & 0.472 & 0.625 & 0.698 & 0.075 & 0.075 & 1.578 \\
\hline
\end{tabular}


Table 3 (Continued)

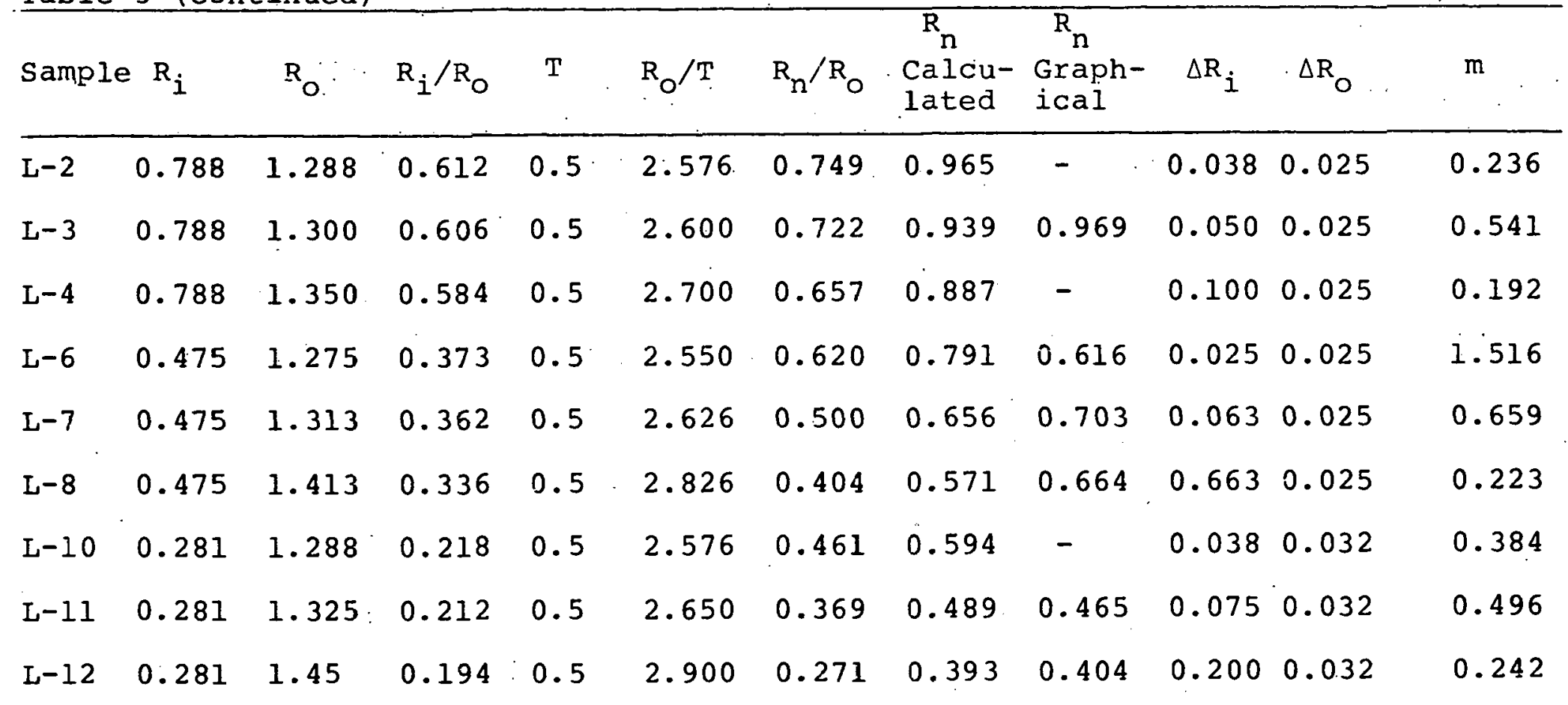


Table 4. Values of the strain components on the slice taken parallel to the roll axis from each of the 70:30 Laminac blocks rolled at $51^{\circ} \mathrm{C}$

\begin{tabular}{|c|c|c|c|c|c|c|}
\hline $\begin{array}{l}\text { Block } \\
\text { Size }\end{array}$ & $\begin{array}{l}\text { Initial } \\
\text { \& } \\
\text { Reduction }\end{array}$ & Position & $\varepsilon_{\mathbf{x}}$ & $\varepsilon_{y}$ & $\varepsilon_{z}$ & $\begin{array}{l}\text { Roll } \\
\text { Speed } \\
\text { (RPM) }\end{array}$ \\
\hline $0.25^{\prime \prime} \times 2 " \times 6 "$ & 7 & $\begin{array}{l}2 \\
5 \\
8\end{array}$ & $\begin{array}{l}0 \\
0 \\
0\end{array}$ & $\begin{array}{l}-0.01 \\
-0.01 \\
-0.01\end{array}$ & $\begin{array}{l}0.01 \\
0.01 \\
0.02\end{array}$ & 0.2 \\
\hline $0.25^{\prime \prime} \times 2 " \times 6 "$ & 14 & $\begin{array}{l}2 \\
5 \\
8\end{array}$ & $\begin{array}{l}0.019 \\
0 \\
0.019\end{array}$ & $\begin{array}{l}-0.011 \\
-0.10 \\
-0.11\end{array}$ & $\begin{array}{l}0.09 \\
0.10 \\
0.09\end{array}$ & 0.2 \\
\hline $0.25^{\prime \prime} \times 2 " \times 6 "$ & 20 & $\begin{array}{l}2 \\
5 \\
8\end{array}$ & $\begin{array}{l}0.046 \\
0 \\
0.024\end{array}$ & $\begin{array}{l}-0.18 \\
-0.16 \\
-0.17\end{array}$ & $\begin{array}{l}0.14 \\
0.16 \\
0.15\end{array}$ & 0.2 \\
\hline $0.5^{\prime \prime} \times 2 " \times 6 "$ & 7 & $\begin{array}{l}2 \\
5 \\
8\end{array}$ & $\begin{array}{l}0 \\
0 \\
0\end{array}$ & $\begin{array}{l}-0.02 \\
-0.02 \\
-0.02\end{array}$ & $\begin{array}{l}0.02 \\
0.02 \\
0.02\end{array}$ & 0.2 \\
\hline $0.5 " \times 2 " \times 6 "$ & 14 & $\begin{array}{l}2 \\
5 \\
8\end{array}$ & $\begin{array}{l}0 \\
0 \\
0\end{array}$ & $\begin{array}{l}-0.10 \\
-0.10 \\
-0.10\end{array}$ & $\begin{array}{l}0.10 \\
0.10 \\
0.10\end{array}$ & 0.2 \\
\hline $0.5 " \times 2 " \times 6 "$ & 20 & $\begin{array}{l}2 \\
5 \\
8\end{array}$ & $\begin{array}{l}0.019 \\
0.009 \\
0\end{array}$ & $\begin{array}{l}-0.11 \\
-0.12 \\
-0.13\end{array}$ & $\begin{array}{l}0.10 \\
0.11 \\
0.13\end{array}$ & 0.2 \\
\hline $0.25^{\prime \prime} \times 1 " \times 6 "$ & 7 & $\begin{array}{l}2 \\
5 \\
8\end{array}$ & $\begin{array}{l}0 \\
0 \\
0\end{array}$ & $\begin{array}{l}-0.05 \\
-0.04 \\
-0.05\end{array}$ & $\begin{array}{l}0.05 \\
0.05 \\
0.04\end{array}$ & 0.2 \\
\hline $0.25 " \times 1 " \times 6 "$ & 14 & $\begin{array}{l}2 \\
5 \\
8\end{array}$ & $\begin{array}{l}0.03 \\
0 \\
0.02\end{array}$ & $\begin{array}{l}-0.14 \\
-0.14 \\
-0.15\end{array}$ & $\begin{array}{l}0.10 \\
0.14 \\
0.12\end{array}$ & 0.2 \\
\hline $0.25^{\prime \prime} \times 1 " \times 6 "$ & 20 & $\begin{array}{l}2 \\
5 \\
8\end{array}$ & $\begin{array}{l}0.07 \\
0.047 \\
0.070\end{array}$ & $\begin{array}{l}-0.20 \\
-0.19 \\
-0.20\end{array}$ & $\begin{array}{l}0.14 \\
0.15 \\
0.14\end{array}$ & 0.2 \\
\hline $0.5^{\prime \prime} \times 1 " x 6 "$ & 7 & $\begin{array}{l}2 \\
5 \\
8\end{array}$ & $\begin{array}{l}-0.011 \\
0 \\
-0.01\end{array}$ & $\begin{array}{l}-0.06 \\
-0.06 \\
-0.06\end{array}$ & $\begin{array}{l}0.07 \\
0.06 \\
0.07\end{array}$ & 0.2 \\
\hline $0.5^{\prime \prime} \times 1 " x 6 "$ & 14 & $\begin{array}{l}2 \\
5 \\
8\end{array}$ & $\begin{array}{l}0 \\
0.025 \\
0\end{array}$ & $\begin{array}{l}-0.06 \\
-0.17 \\
-0.06\end{array}$ & $\begin{array}{l}0.06 \\
0.05 \\
0.06\end{array}$ & \\
\hline $1 " x 1 " \times 6$ " & 7 & $\begin{array}{r}10 \\
2 \\
3 \\
4 \\
5 \\
6 \\
8 \\
9\end{array}$ & $\begin{array}{c}0.03 \\
-0.006 \\
0.036 \\
0.01 \\
0.008 \\
0.008 \\
-0.006 \\
0.036\end{array}$ & $\begin{array}{l}-0.05 \\
-0.03 \\
-0.06 \\
-0.03 \\
-0.04 \\
-0.04 \\
-0.03 \\
-0.06\end{array}$ & $\begin{array}{l}0.03 \\
0.03 \\
0.02 \\
0.03 \\
0.04 \\
0.04 \\
0.03 \\
0.02\end{array}$ & 0.2 \\
\hline
\end{tabular}


Table 4 (Continued)

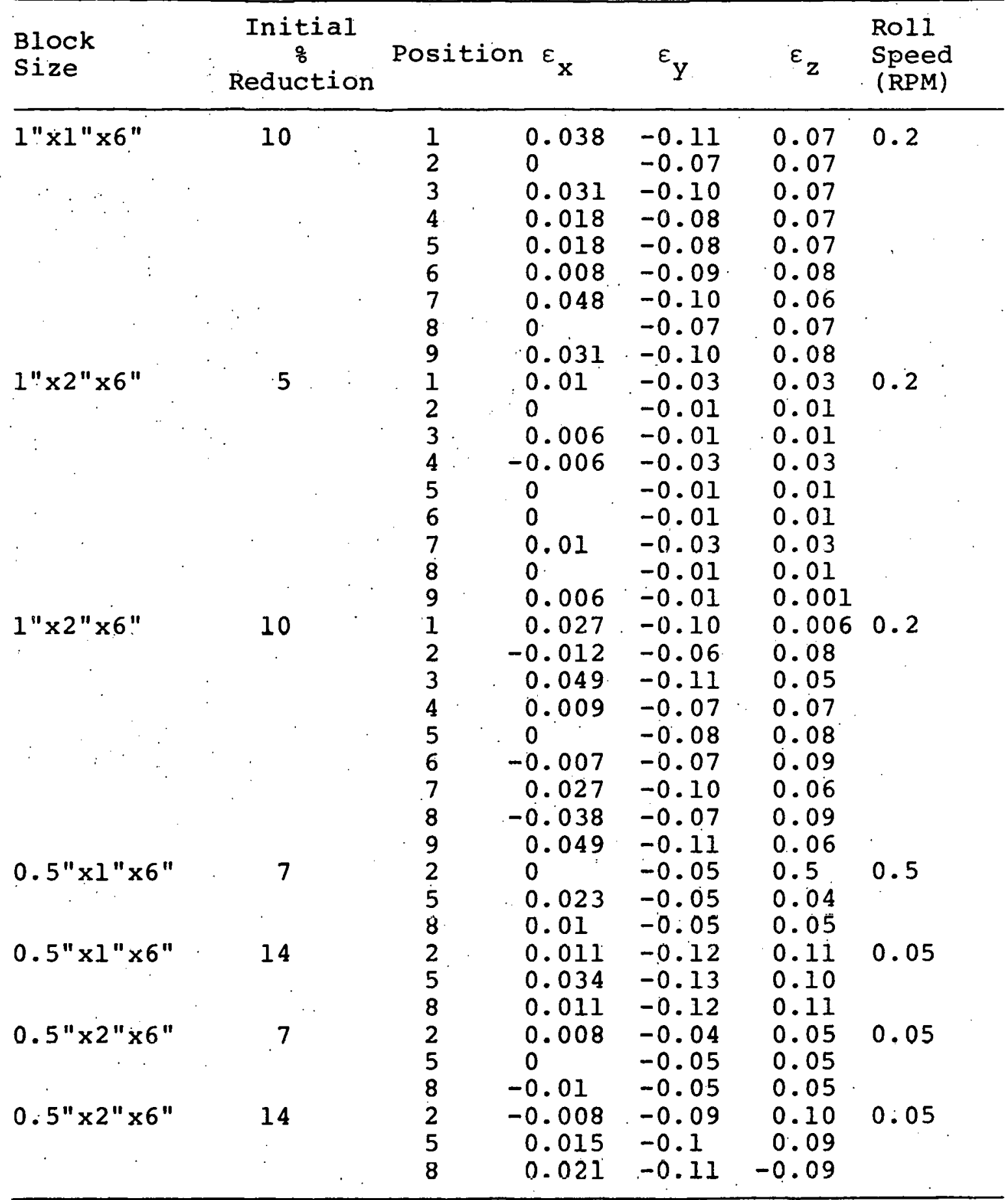



Table 5. Effect of roll speed on strain distribution $\left(\varepsilon_{x}\right)$ at the edges of rolled
$70: 30$ Laminac blocks.

\begin{tabular}{|c|c|c|c|c|c|}
\hline Block Size & $\varepsilon_{x}(2)$ & $\varepsilon_{\mathrm{x}}(5)$ & $\varepsilon_{\mathrm{x}}(8)$ & $\begin{array}{l}\text { Original } \\
\text { Reduction } \\
\text { (Residual) }\end{array}$ & $\begin{array}{l}\text { Roll } \\
\text { Speed } \\
\text { (RPM) }\end{array}$ \\
\hline $\begin{array}{l}0.5 " x 1 " x 6^{\prime \prime} \\
0.5 " x 1 " x 6 \text { " }\end{array}$ & $\begin{array}{r}-0.01 \\
0.00\end{array}$ & $\begin{array}{l}0.00 \\
0.023\end{array}$ & $\begin{array}{l}-0.01 \\
-0.01\end{array}$ & $\begin{array}{ll}7 & (3.4) \\
7 & (5.8)\end{array}$ & $\begin{array}{l}0.20 \\
0.05\end{array}$ \\
\hline $\begin{array}{l}0.5 " \times 2 " \times 6 " \\
0.5 " \times 2 " \times 6 "\end{array}$ & $\begin{array}{l}0.00 \\
0.008\end{array}$ & $\begin{array}{l}0.00 \\
0.00\end{array}$ & $\begin{array}{r}0.00 \\
-0.01\end{array}$ & $\begin{array}{ll}7 & (4.8) \\
7 & (5.8)\end{array}$ & $\begin{array}{l}0.20 \\
0.05\end{array}$ \\
\hline $\begin{array}{l}0.5 " x I " x 6 " \\
0.5 " x 1 " x 6 \text { " }\end{array}$ & $\begin{array}{l}0.00 \\
0.011\end{array}$ & $\begin{array}{l}0.025 \\
0.034\end{array}$ & $\begin{array}{l}0.00 \\
0.011\end{array}$ & $\begin{array}{ll}14 & (11.8) \\
14 & (12.8)\end{array}$ & $\begin{array}{l}0.20 \\
0.05\end{array}$ \\
\hline $\begin{array}{l}0.5^{\prime \prime} \times 2 " \times 6 " 1 \\
0.5^{\prime \prime} \times 2 " \times 6 "\end{array}$ & $\begin{array}{c}0.00 \\
-0.008\end{array}$ & $\begin{array}{l}0.00 . \\
0.015\end{array}$ & $\begin{array}{l}0.00 \\
0.021\end{array}$ & $\begin{array}{ll}14 & (11.2) \\
14 & (13.4)\end{array}$ & $\begin{array}{l}0.20 \\
0.05\end{array}$ \\
\hline
\end{tabular}


APPENDIX B : FIGURES 


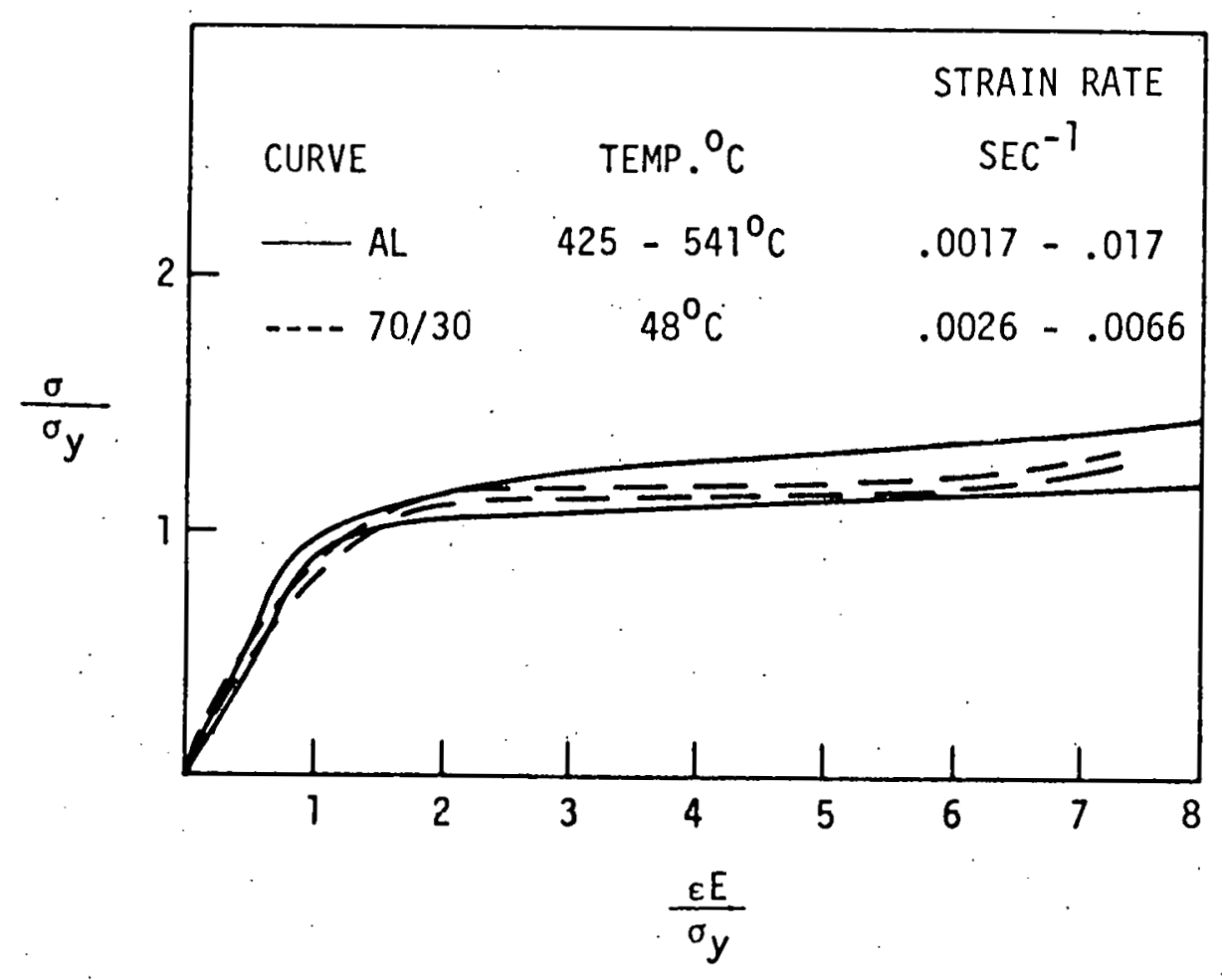

Figure 1. Comparison of stress-strain curves for aluminum and 70:30 Laminac mixture plotted according to Rambergosgood relation from Ref. 34 . 


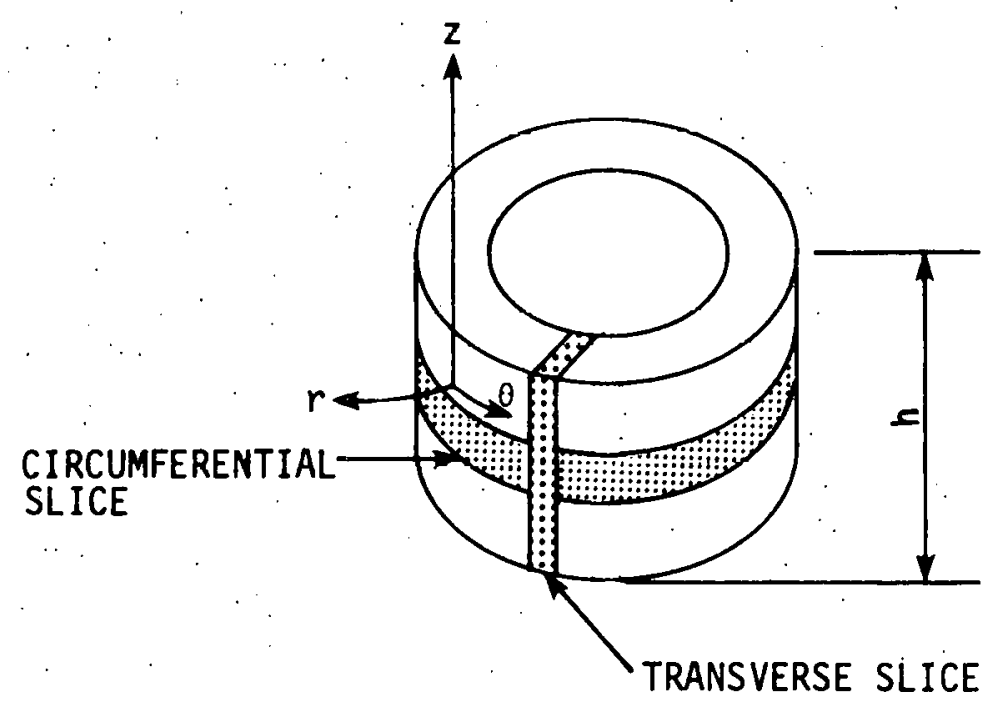

Figure 2. Sketch to show how transverse and circumferential slices were taken from the cumpressed rings at $51^{\circ} \mathrm{C}$. 

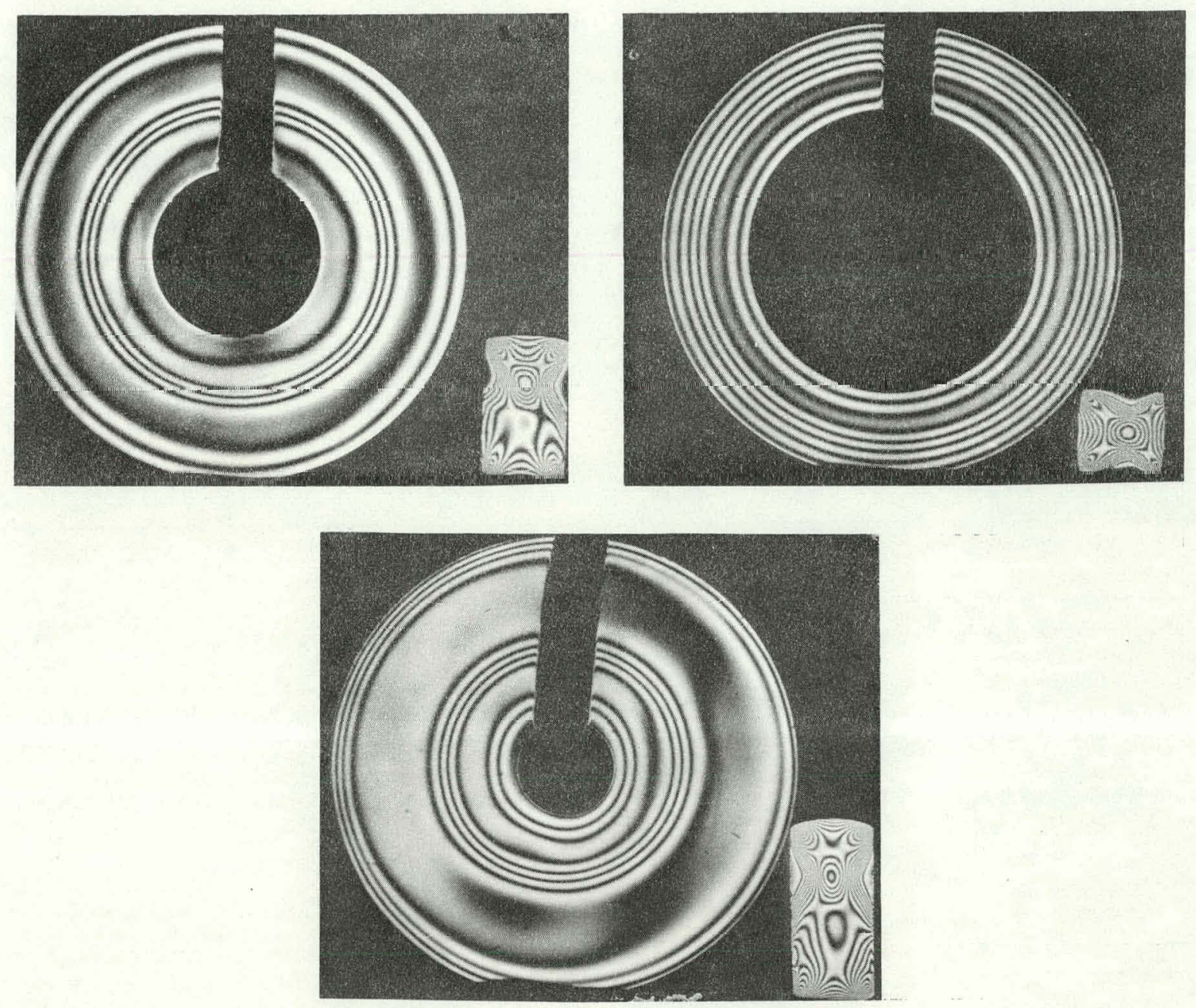

Figure 3a. Dark-field isocromatic fringe patterns of the circumferential and transverse slices taken from the rings compressed at $51^{\circ} \mathrm{C}$ on smooth platens 

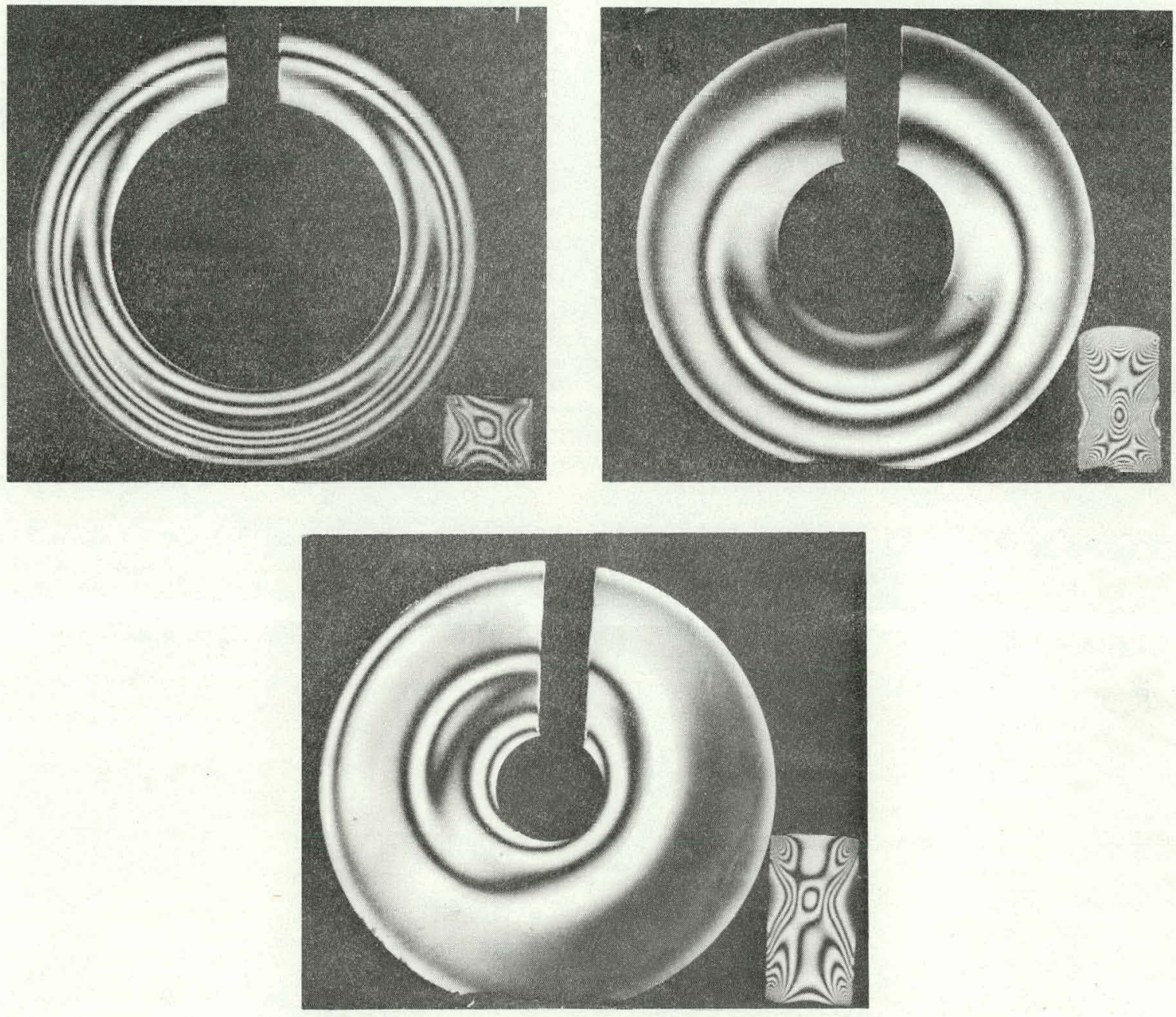

Figure 3b. Dark-field isocromatic fringe patterns of the circumferential and transverse slices taken from the rings compressed at $51^{\circ} \mathrm{C}$ on rough platens 

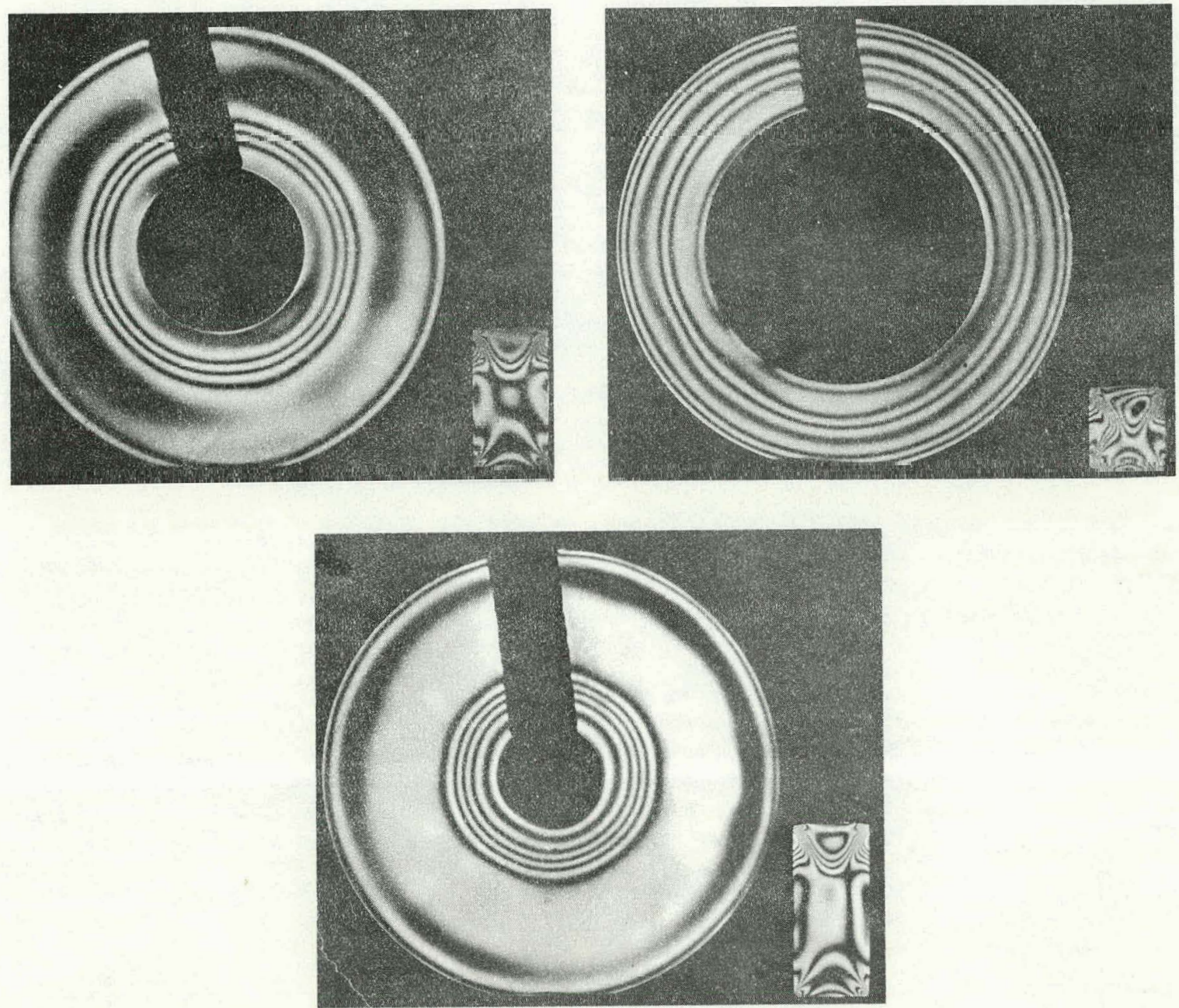

Figure 3c. Dark field isocromatic fringe patterns of the circumferential and transverse slices taken from the rings compressed at $51^{\circ} \mathrm{C}$ on lubricated platens 


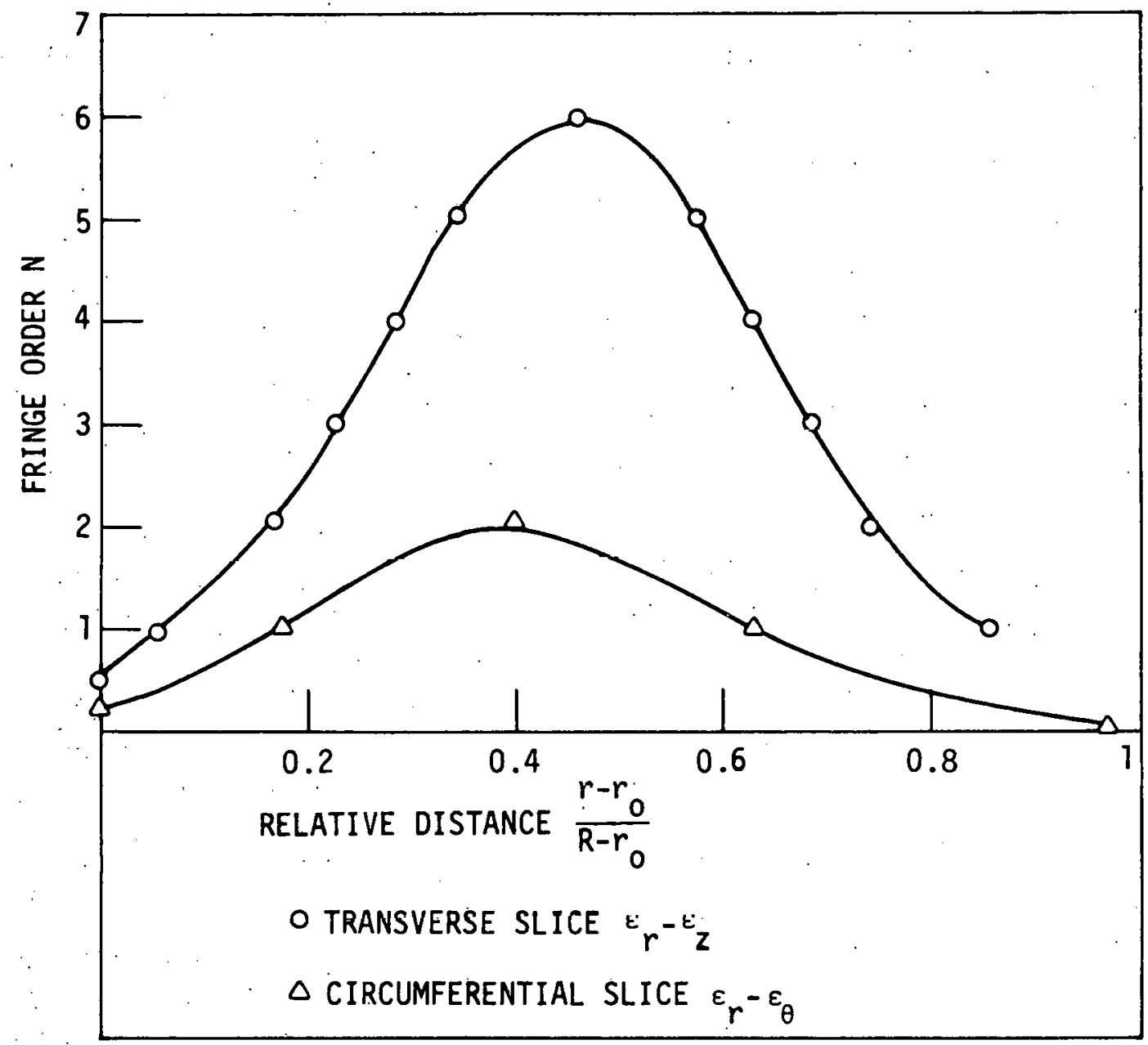

Figure 4.: A typical plot of photoplastic fringe order $\mathrm{N}$ against the relative distance $r-r_{0}$ along the midsection of the ring. $\frac{r_{0}}{R-r_{0}}$ 
(a)
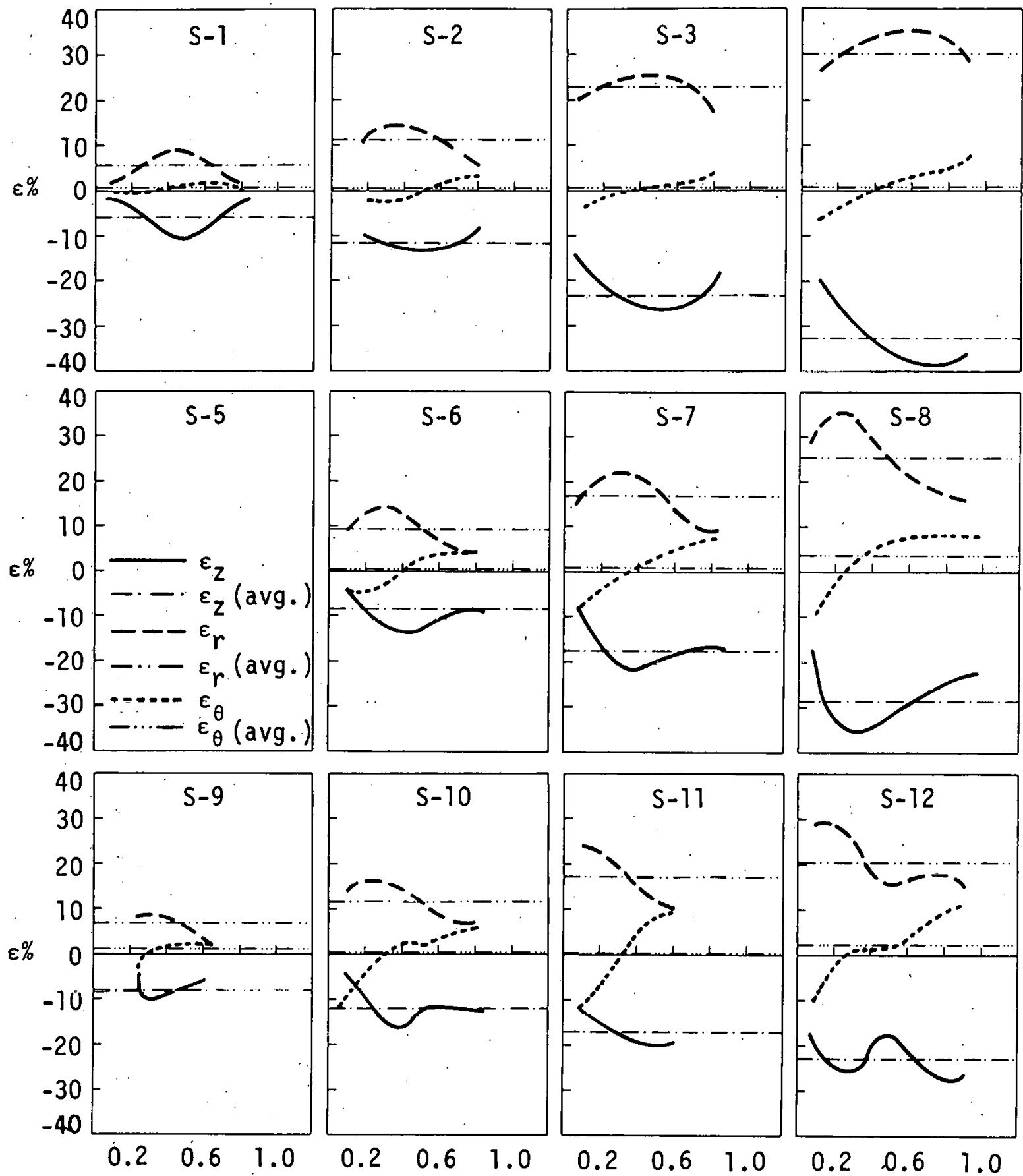

$$
\frac{r-r_{0}}{R-r_{0}}
$$

Figure 5. The three dimensional strain distributions along the mid-section of the rings compressed at $51^{\circ} \mathrm{C}$ on (a) smooth, (b) rough, and (c) lubricated smooth platens, respectively. 
(b)
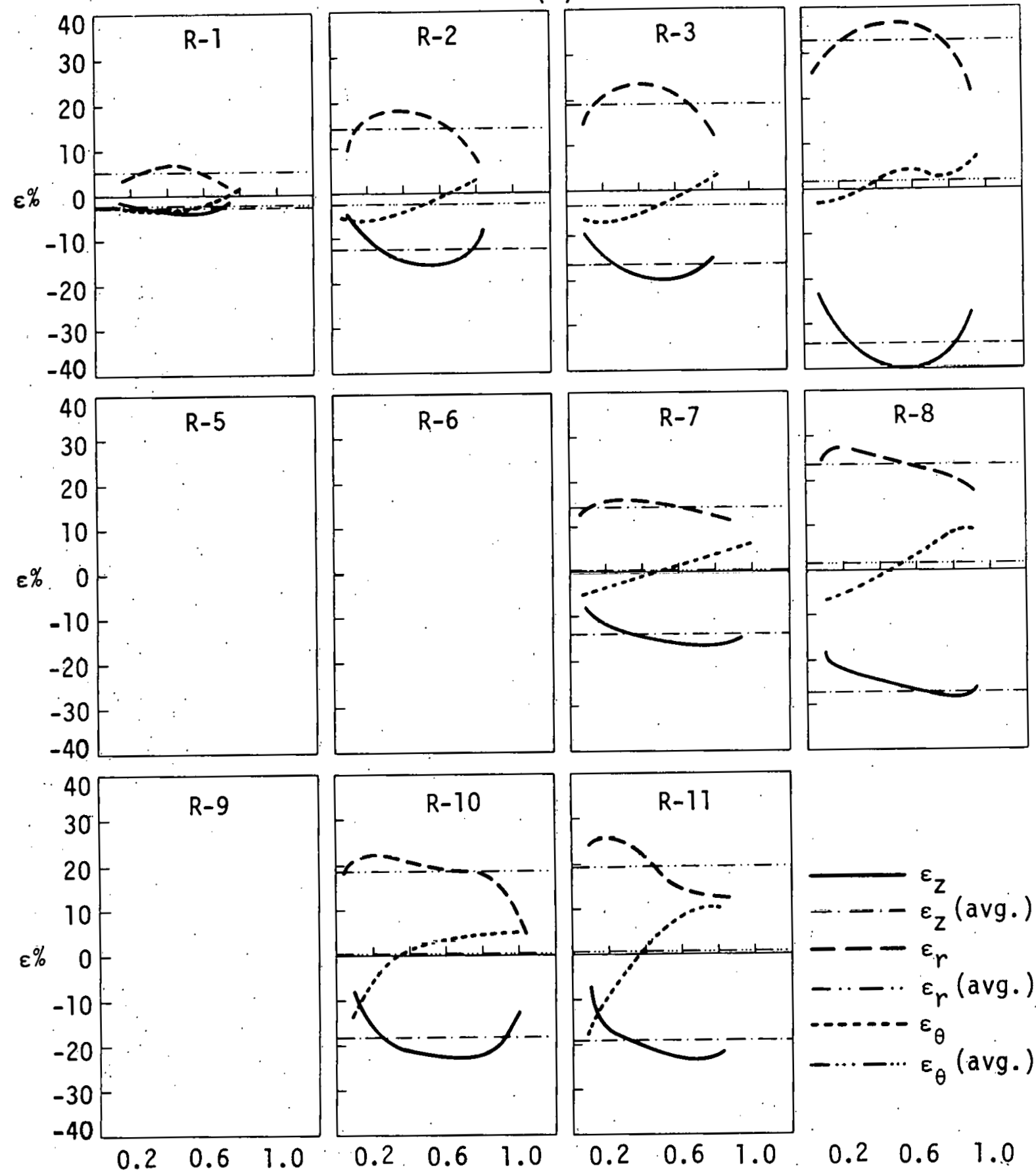

$$
\frac{r-r_{0}}{R-r_{0}}
$$

Figure 5 (Continued) 
(c)
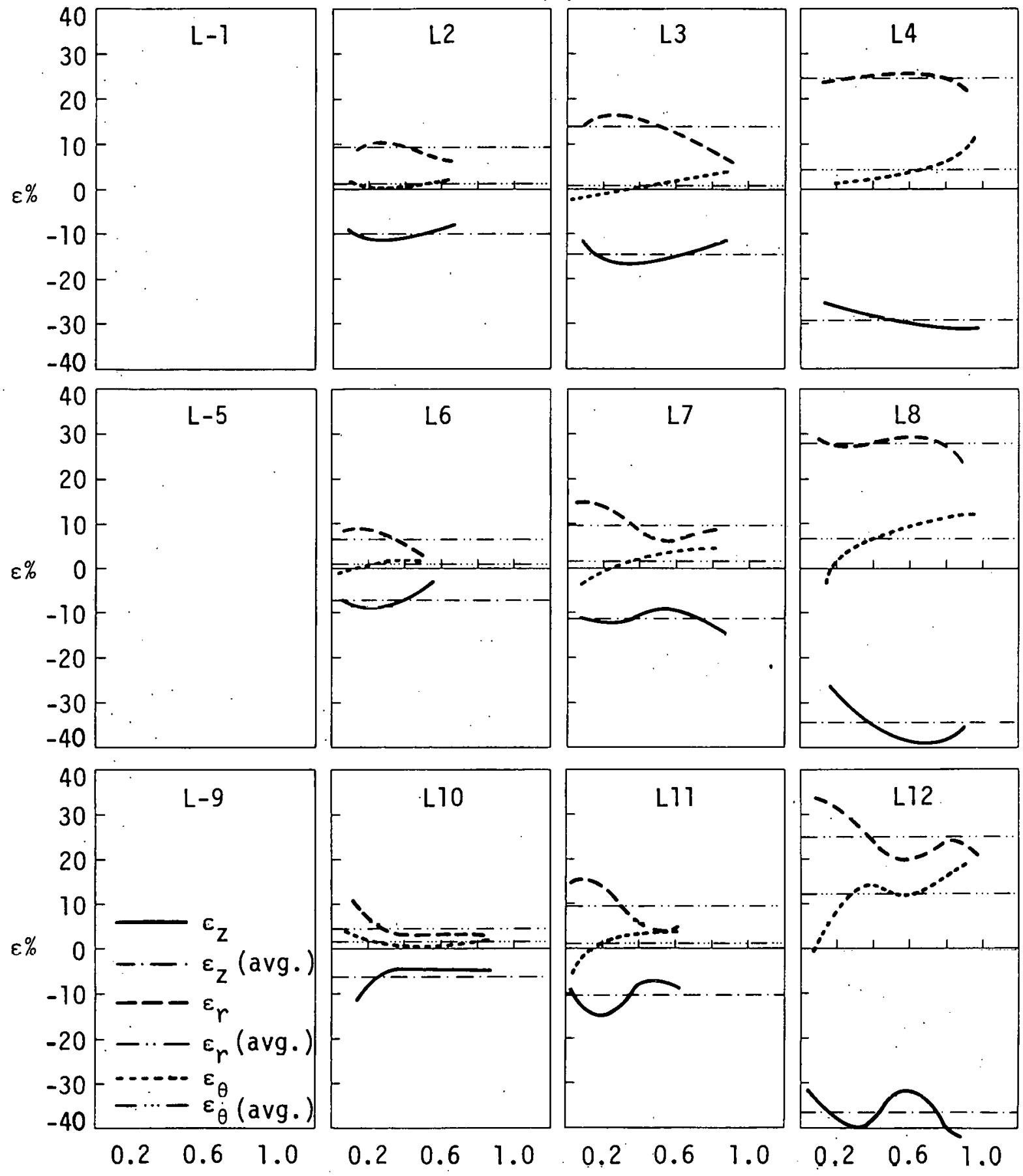

$$
\frac{r-r_{0}}{R-r_{0}}
$$

Figure 5 (Continued) 


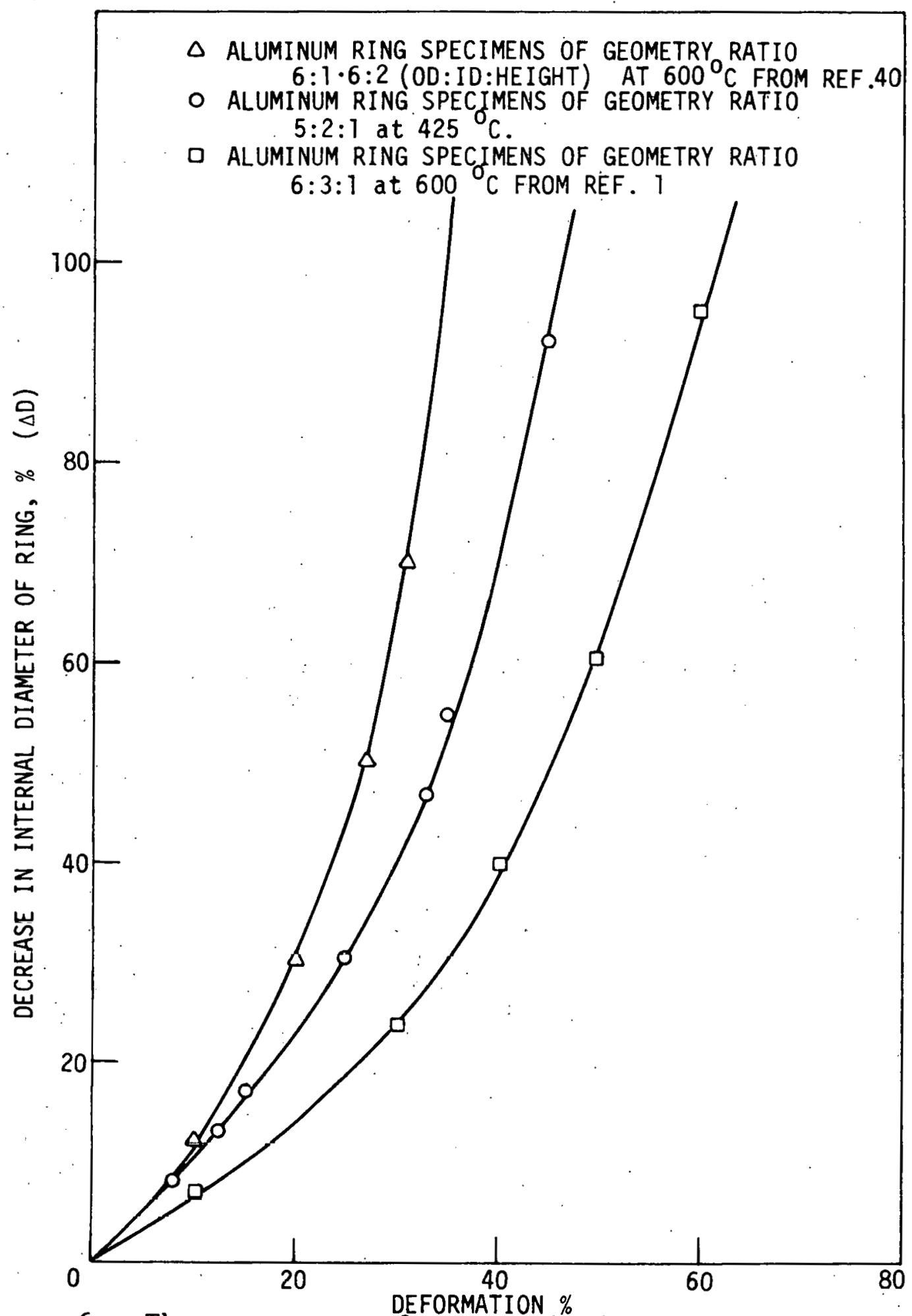

Figure 6. The percentage decrease in internal diameter, $\triangle D$, of aluminum rings compressed at $425^{\circ} \mathrm{C}$ versus percentage deformation. 


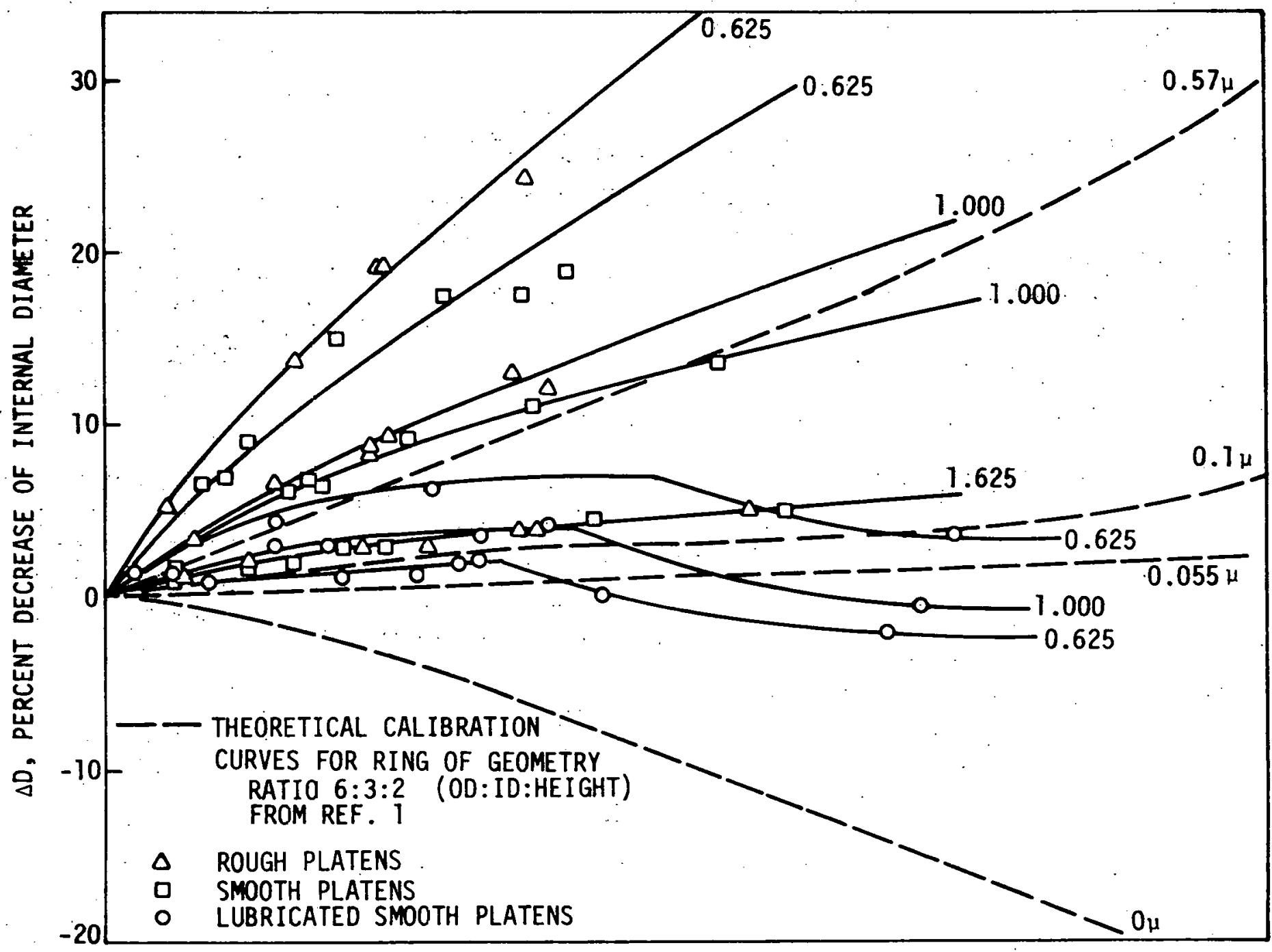

PERCENT RETAINED REDUCTION IN HEIGHT OF DISK

Figure 7. The percentage decrease in internal diameter, $\triangle D$, of the 70:30 Laminac rings compressed at $51^{\circ} \mathrm{C}$ on smooth, rough, and lubricated smooth platens versus retained percentage deformation. 


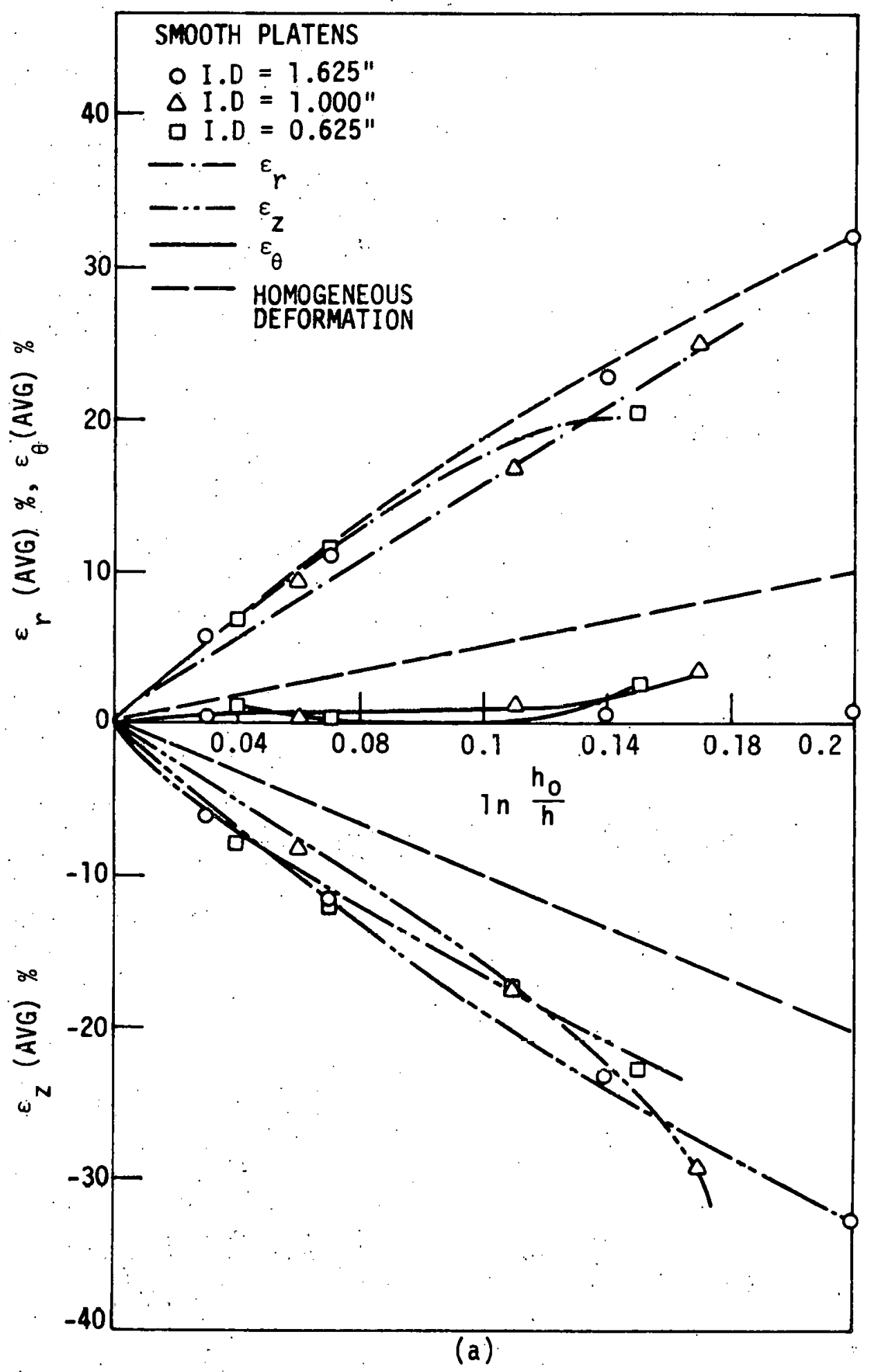

Figure 8. Variation of the average strains at the midsection in upset rings on, (a) smooth platens, (b) rough platens, and (c) lubricated smooth platens. 


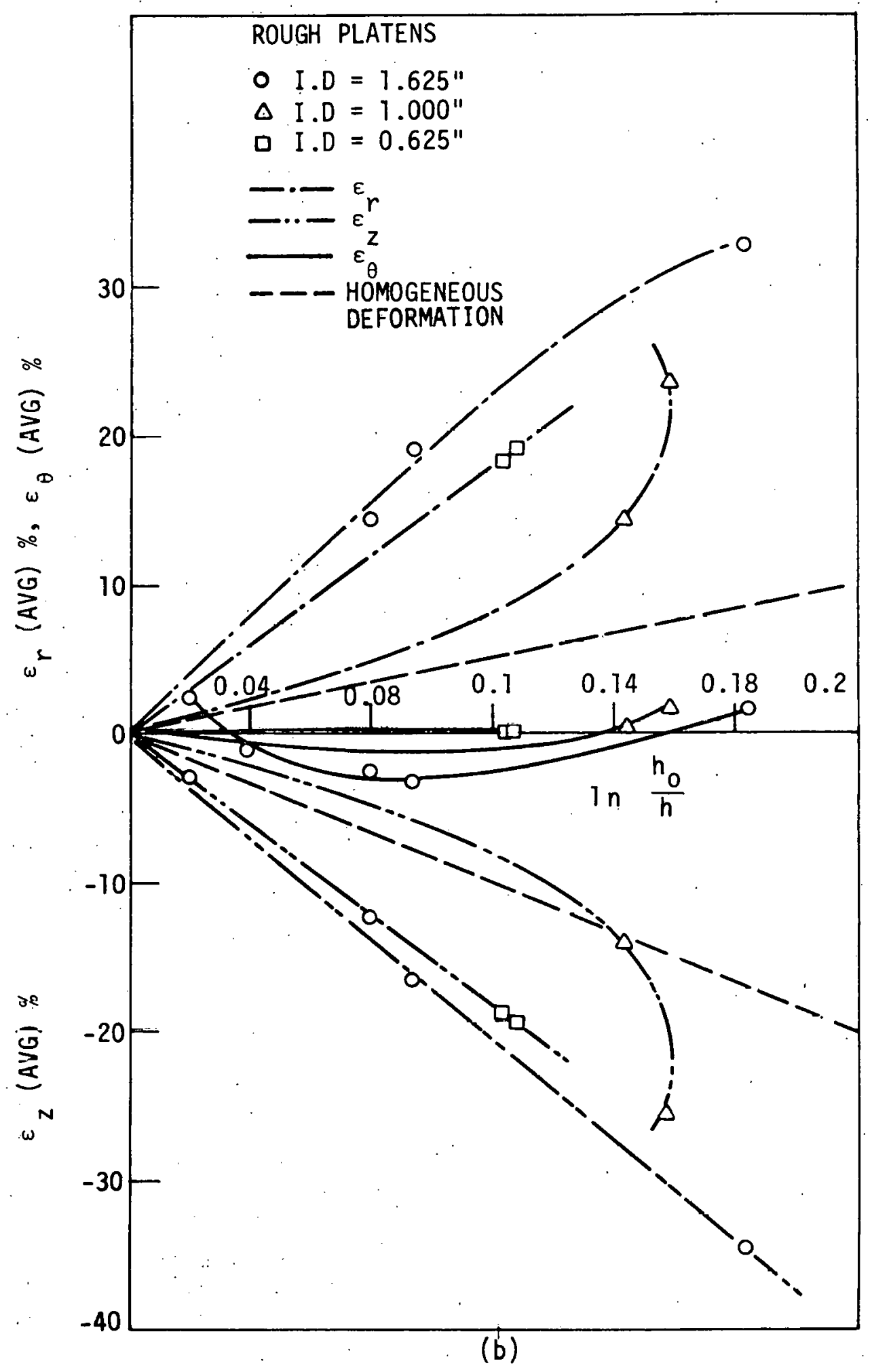

Figure 8 (Continued) 


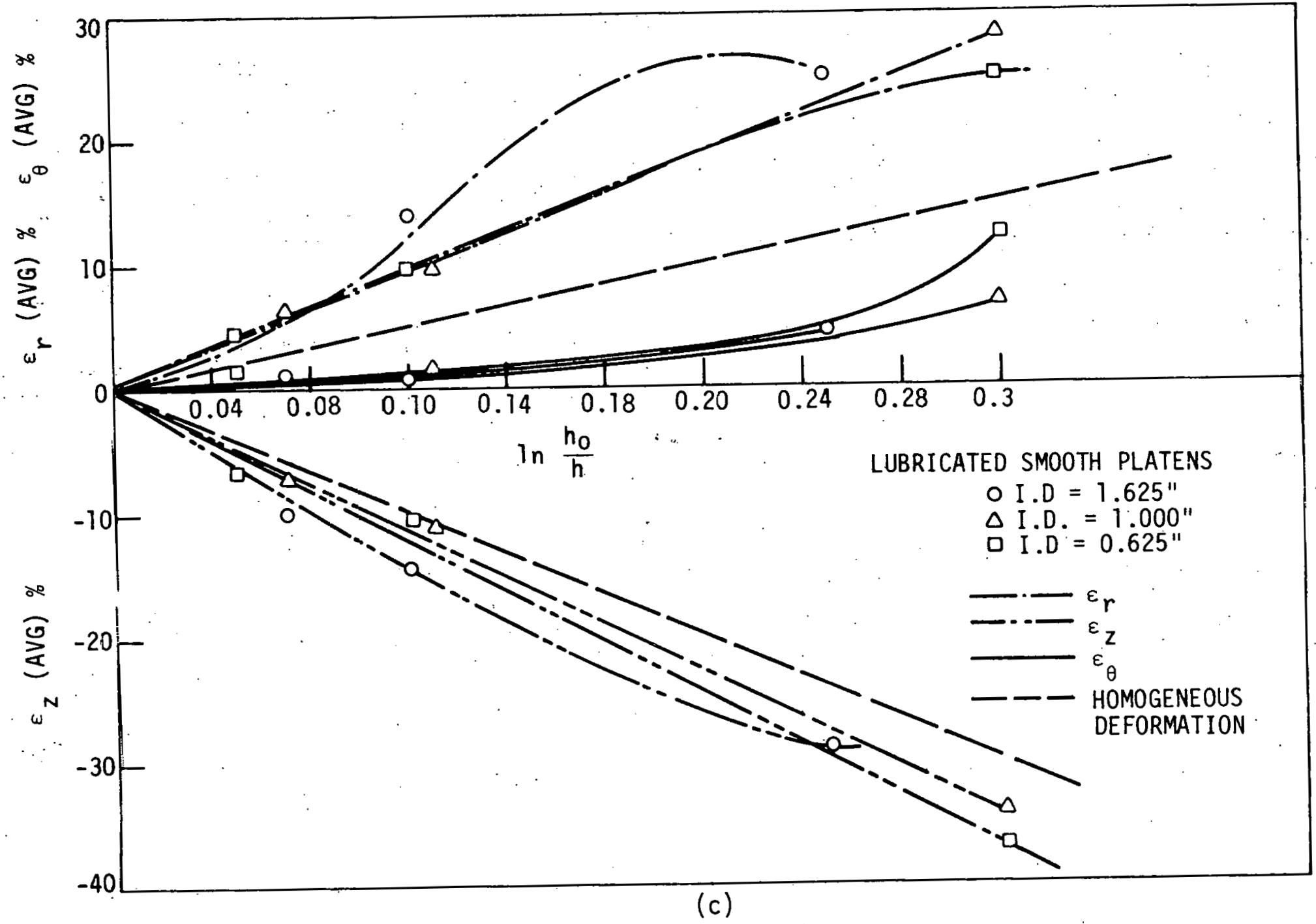

Figure 8 (Continued) 

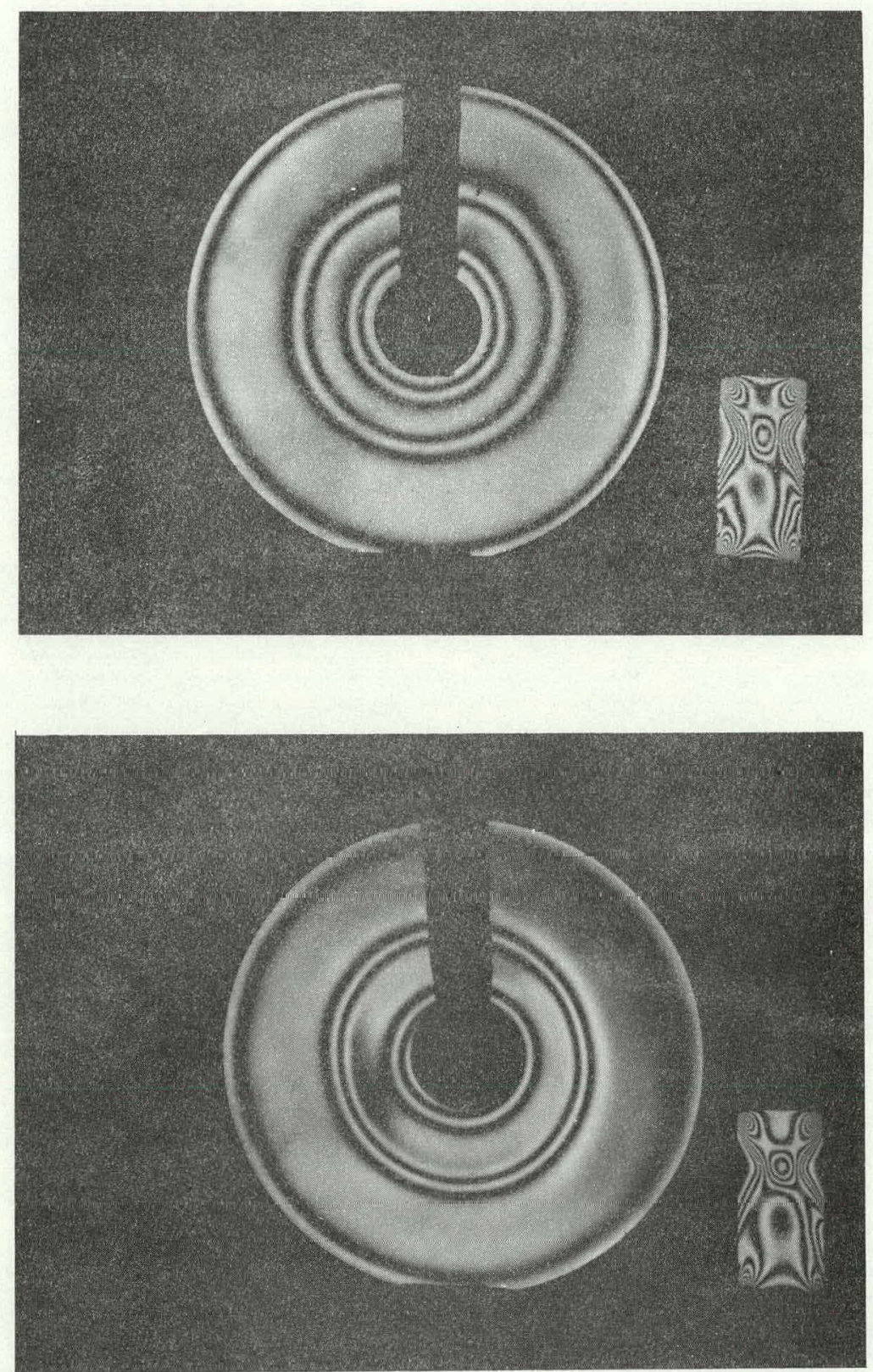

Figure 9. Dark-field isocromatic fringe patterns of the circumferential and transverse slices taken from the rings compressed at $51^{\circ} \mathrm{C}$ on smooth platens;

(a) $8 \%$ reduction with load held for five minutes; (b) $20 \%$ reduction with load removed immediately.. 

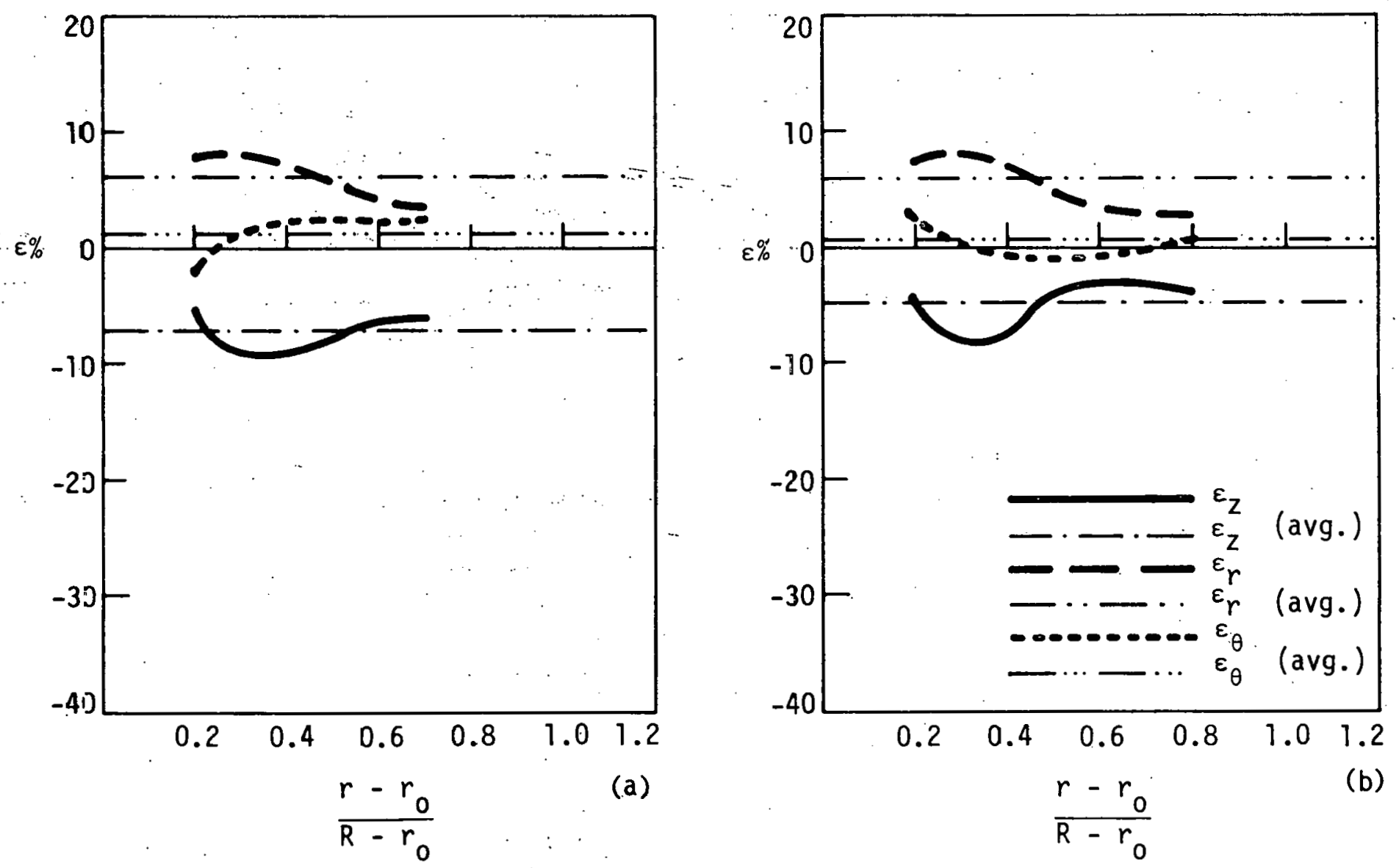

Figure 10. The three dimensional strain distributions along the mid-section of the rings compressed at $51^{\circ} \mathrm{C}$ on smooth platens; (a) 88 reduction with load held for five minutes; (b) 208 reduction with load removed immediately. 


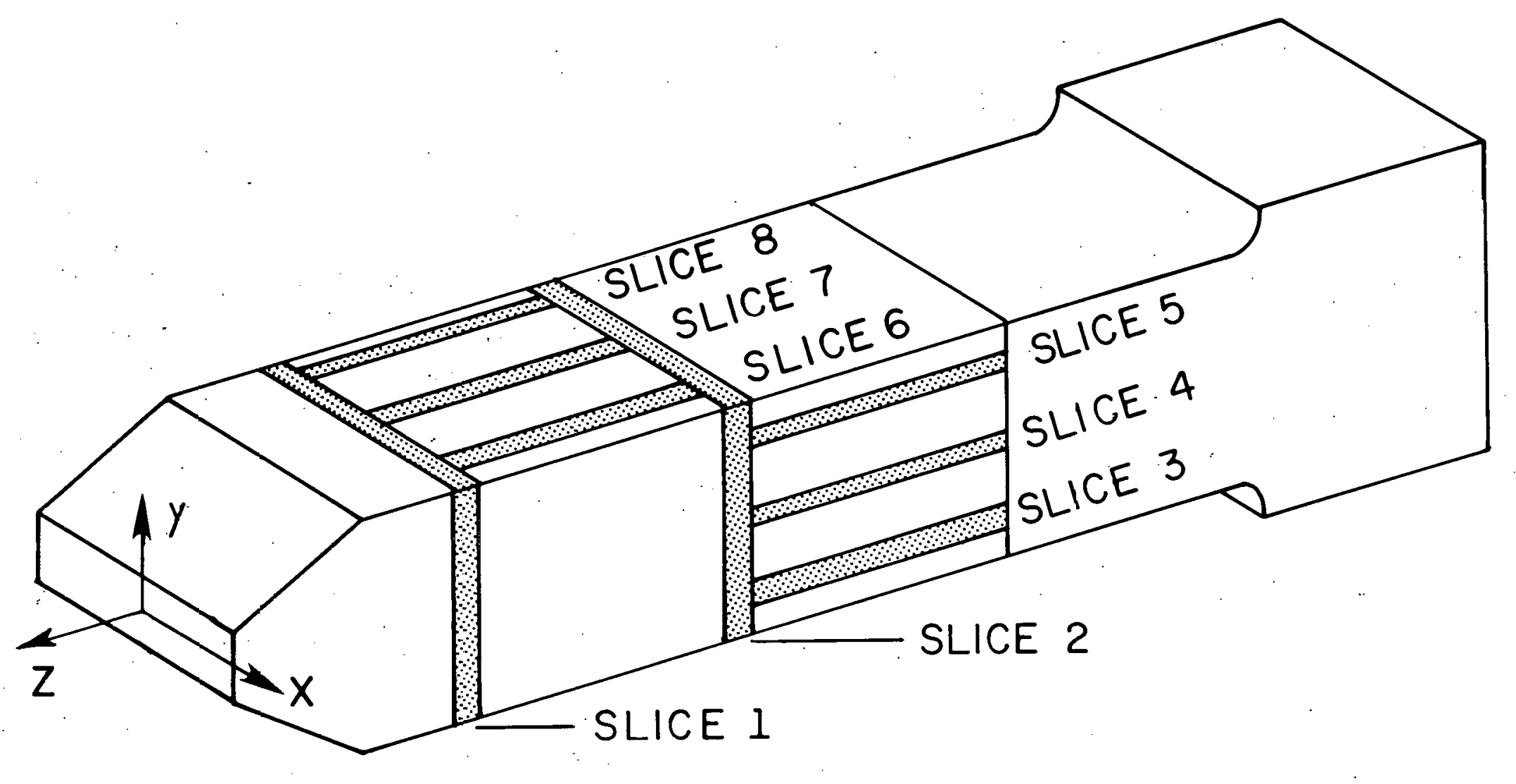

$\underset{\infty}{\infty}$

Figure 11. Schematic illustration of the numbering and orientations of sections sliced from a rolled block for photoplastic studies. 


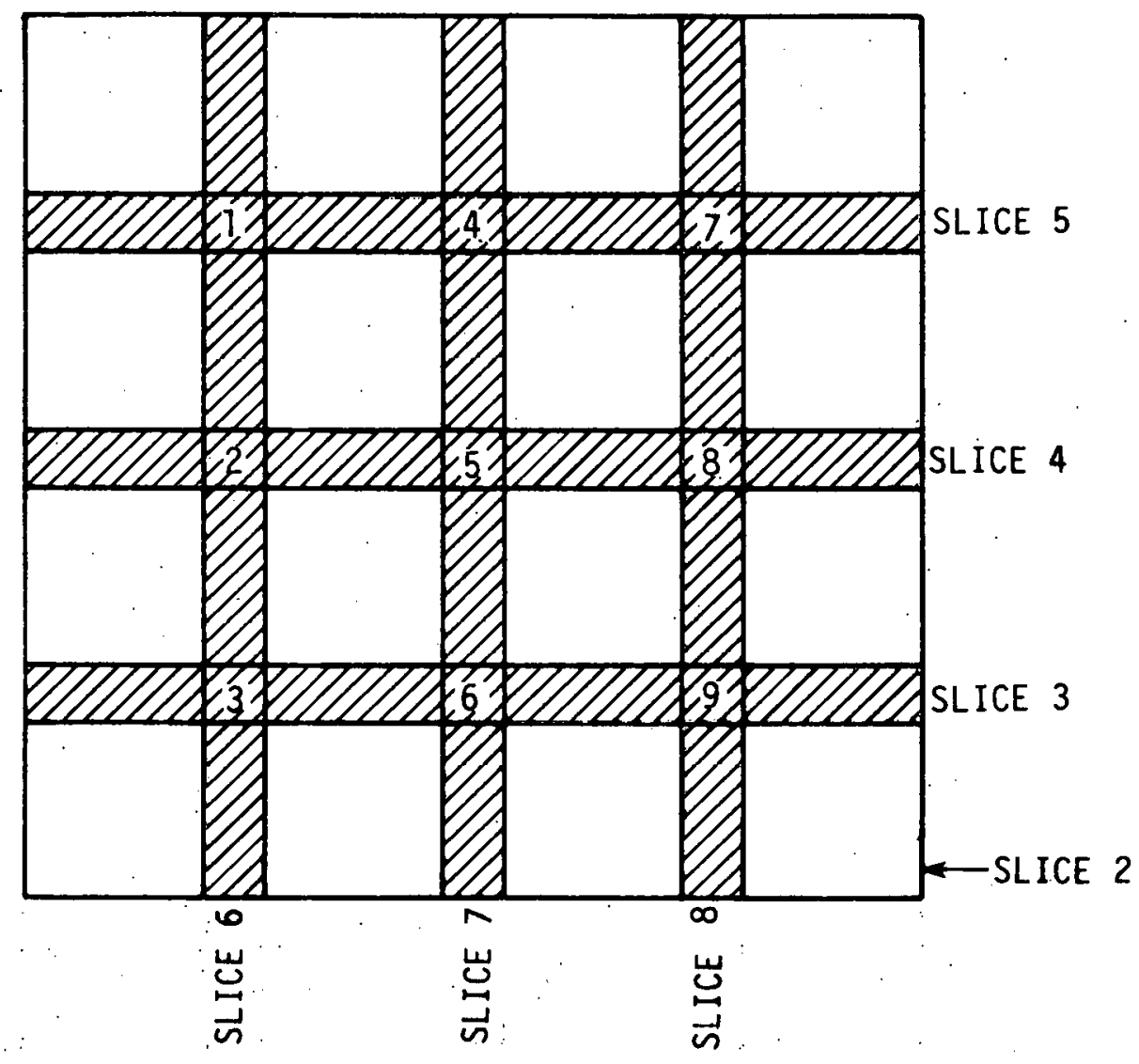

Figure 12. Two dimensional views of slices 2 to 9 showing their points of intersections. 


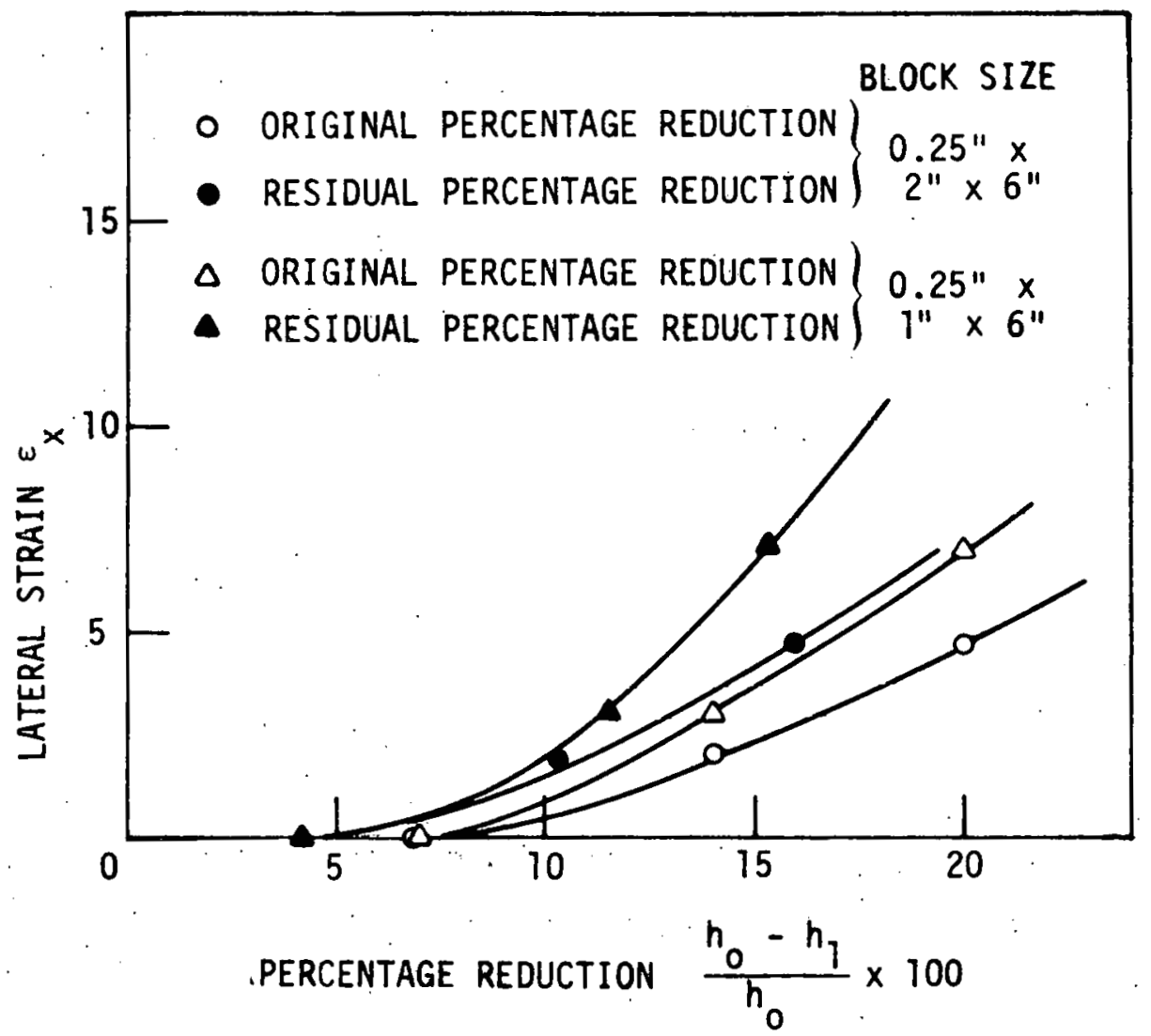

Figure 13. Increase of strain $\varepsilon_{x}$ on the edges of the rolled blocks with increase in percentage reductions. 


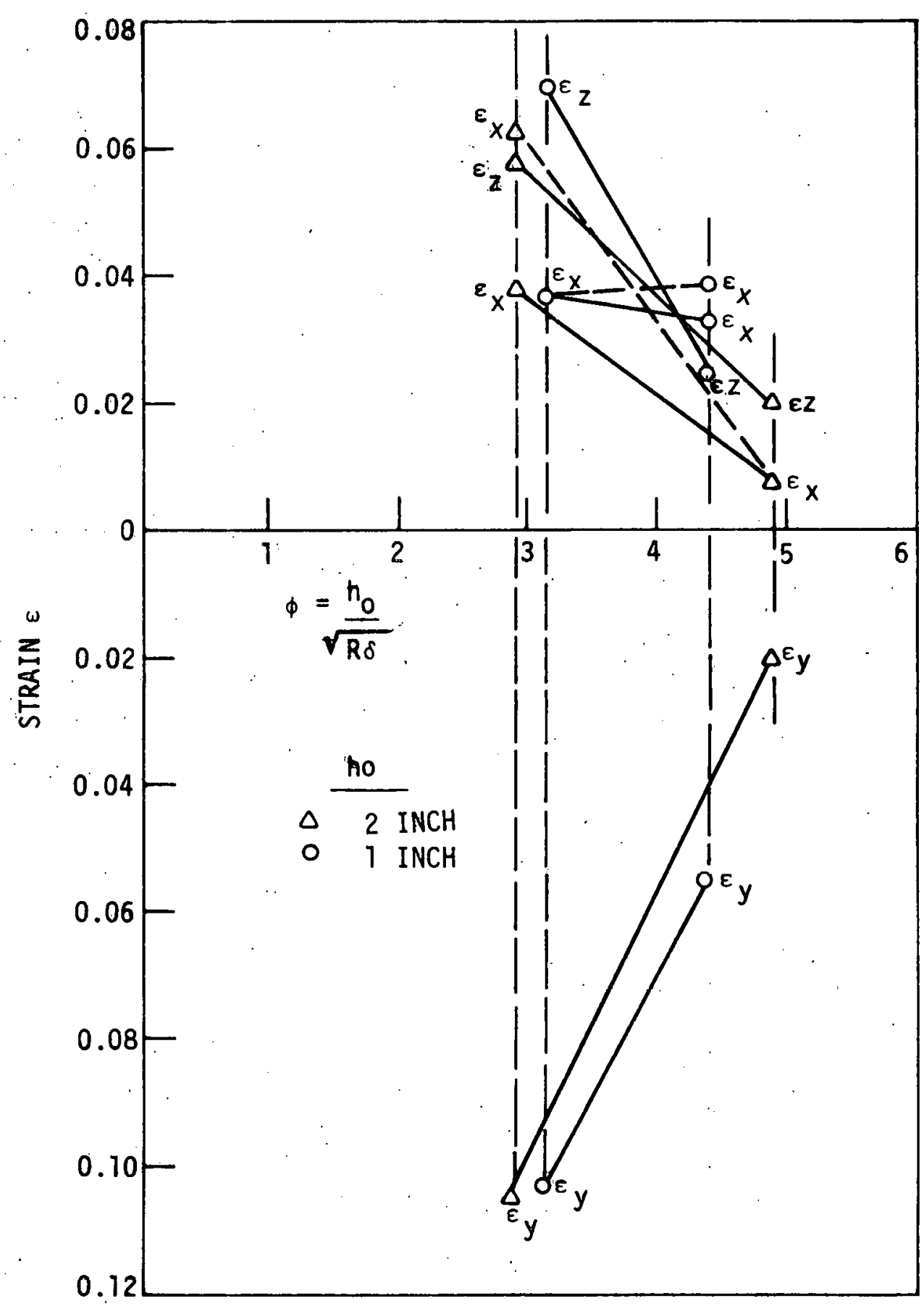

Figure 14. Effect of width on double-bulge formation. 